NBER WORKING PAPER SERIES

\title{
SLICING THE PIE: \\ QUANTIFYING THE AGGREGATE AND DISTRIBUTIONAL EFFECTS OF TRADE
}

\author{
Simon Galle \\ Andrés Rodríguez-Clare \\ Moises Yi \\ Working Paper 23737 \\ http://www.nber.org/papers/w23737 \\ NATIONAL BUREAU OF ECONOMIC RESEARCH \\ 1050 Massachusetts Avenue \\ Cambridge, MA 02138 \\ August 2017
}

We are grateful to seminar participants at BI, Columbia, Edinburgh, Fed Board of Governors, LSE, Mannheim, Paris-Sud, Rochester, UC Berkeley, UC Merced, USC, the World Bank, the Danish International Economics Workshop, the Oslo European Strains Workshop, the NBER Summer Institute, the Nordic Register Data and Economic Modelling Meeting, and the Princeton IES Summer Workshop for helpful comments and suggestions. We also benefited from useful comments from Dominick Bartelme, Fenella Carpena, Arnaud Costinot, Kerem Cosar, Ben Faber, Pablo Fajgelbaum, Pete Klenow, Patrick Kline, Plamen Nenov, Allan Sorensen, Stephen Redding, Ben Schoefer and Jonathan Vogel. We are grateful to David Dorn and Gordon Hanson for sharing their data sources and code. Daniel Haanwinckel, Yusuf Mercan, Preston Mui, Mathieu Pedemonte and Roman Zarate provided excellent research assistance. We are grateful for financial support from the Clausen Center for International Business and Policy. This material is based upon work supported by the National Science Foundation under Grant Number 1561854. Any opinions and conclusions expressed herein are those of the authors and do not necessarily represent the views of the Clausen Center, the National Science Foundation or the U.S. Census Bureau. The views expressed herein are those of the authors and do not necessarily reflect the views of the National Bureau of Economic Research.

NBER working papers are circulated for discussion and comment purposes. They have not been peer-reviewed or been subject to the review by the NBER Board of Directors that accompanies official NBER publications.

(C) 2017 by Simon Galle, Andrés Rodríguez-Clare, and Moises Yi. All rights reserved. Short sections of text, not to exceed two paragraphs, may be quoted without explicit permission provided that full credit, including $(\odot$ notice, is given to the source. 
Slicing the Pie: Quantifying the Aggregate and Distributional Effects of Trade Simon Galle, Andrés Rodríguez-Clare, and Moises Yi

NBER Working Paper No. 23737

August 2017

JEL No. F1

\section{ABSTRACT}

We develop a multi-sector gravity model with heterogeneous workers to quantify the aggregate and group-level welfare effects of trade. We estimate the model using the structural relationship between China-shock driven changes in manufacturing employment and average earnings across US groups defined by commuting zone and education. We find that the China shock increases average welfare but some groups experience losses as high as five times the average gain. Adjusted for plausible measures of inequality aversion, gains in social welfare are positive and only slightly lower than with the standard aggregation.

Simon Galle

Department of Economics

BI Norwegian Business School

0442 Oslo

Norway

sgalle@econ.berkeley.edu

Andrés Rodríguez-Clare

University of California at Berkeley

Department of Economics

Berkeley, CA 94720-3880

and NBER

andres1000@gmail.com
Moises Yi

U.S. Census Bureau

moisesyi@gmail.com 


\section{Introduction}

The recent empirical literature has made economists less sanguine about the overall benefits from increased trade integration. Although the notion that there are losers from trade is one of the oldest propositions in the field, recent empirical work exemplified most prominently by Autor, Dorn and Hanson (2013) has shown that the distributive implications of trade shocks in developed countries are stronger and more persistent than previously believed. ${ }^{1}$ In their survey of this work, Autor, Dorn and Hanson (2016) conclude that "it is incumbent on the literature to more convincingly estimate the gains from trade, such that the case for free trade is not based on the sway of theory alone, but on a foundation of evidence that illuminates who gains, who loses, by how much, and under what conditions." In this paper we take a step in this direction - we develop and estimate a multi-sector gravity model of trade with heterogeneous labor and use it to quantify the group-level and aggregate welfare effects of the China shock and overall trade in the United States.

Our model combines three components: a multi-sector version of the Eaton and Kortum (2002) model as in Costinot, Donaldson and Komunjer (2012); a Roy model of the allocation of heterogeneous labor to sectors with a Fréchet distribution as in Lagakos and Waugh (2013); and the existence of different labor groups differing in their pattern of comparative advantage across sectors. The model yields a simple expression for the group-level welfare effects of trade that generalizes the formula previously shown by Arkolakis, Costinot and Rodríguez-Clare (2012) (henceforth ACR) to be valid for a wide class of gravity models. Compared to the ACR formula, ours has an extra term that captures the group-level effects of trade through changes in the vector of sectorspecific wages. Thus, following a logic similar to that in the the specific-factors model, groups with high employment shares in sectors that experience strong increases in import competition will fare worse than other groups. The strength of these distributional effects depends on the shape parameter of the Fréchet distribution, $\kappa$, which governs the degree of labor heterogeneity across sectors: if $\kappa \rightarrow 1$ then our model yields the same welfare implications as the one with sector-specific labor and distributional effects are strongest, while if $\kappa \rightarrow \infty$ then we are back to the single ACR formula applying

\footnotetext{
${ }^{1}$ For a brief intellectual history on the debate about trade and inequality, see Goldberg (2015).
} 
to all groups.

Inspired by Autor et al. (2013) (henceforth ADH), our quantitative analysis focuses on the effect of the China shock on United States workers grouped according to commuting zone and education level. Not only is the focus on local labor markets important in its own right, but it also allows us to build on the empirical strategy developed by $\mathrm{ADH}$ to arrive at a credible estimate of $\kappa$. We employ an instrumental variable approach where the first stage estimates the group-level effect of the China shock on manufacturing employment, a regression corresponding to the reduced-form of one of the central regressions in $\mathrm{ADH}$. The second stage then exploits the model-implied relationship between the projected change in the share of employment in non-manufacturing (one of the sectors in the model) and group-level average earnings. The estimation yields a value for $\kappa$ around 2, which is in line with estimates of this Roy-Fréchet parameter in related contexts (e.g., Adao, Arkolakis and Esposito 2017, Burstein, Morales and Vogel 2015 and Hsieh, Hurst, Jones and Klenow 2013).

Armed with our estimate of $\kappa$, we calibrate the China shock following a strategy similar to that proposed by Caliendo, Dvorkin and Parro (2015). Subsequently, we use the comparative-statics methodology in Dekle, Eaton and Kortum (2008) to compute the group-level and aggregate welfare effects of the China shock in the United States. We find that a small but non-negligible number of groups representing $6.7 \%$ of the population suffer welfare losses, and that those losses can be as high as five times the average gains. The welfare effects are spatially correlated, implying the existence of regions (e.g., southern Appalachia) where most groups tend to experience low or negative effects. To compute the aggregate welfare effects of the trade shock, we ignore the possibility that losers are compensated and use a social welfare function with inequality aversion as in Atkinson (1970). ${ }^{2}$ We obtain the standard aggregation as a special case with no inequality aversion. Initially poorer groups fare slightly worse after the shock, implying a downward pull in the inequality-adjusted welfare gains. However, we argue that for plausible measures of inequality aversion social welfare still increases with the China shock and this increase is similar to the welfare gains without inequality aver-

\footnotetext{
${ }^{2}$ Recent papers that pursue a similar strategy in the trade context are Antras, de Gortari and Itskhoki (2016) and Carrère, Grujovic and Robert-Nicoud (2015). Antras et al. (2016) also considers the distortions associated with compensation and quantifies the associated effect on the gains from trade.
} 
sion. ${ }^{3}$

Moving beyond the China shock, we also use our model to compute the group-level and aggregate gains from trade, defined as in ACR as the negative of the losses from moving to autarky. We again find that a small set of groups lose from trade, with one group experiencing losses of $3.2 \%$, twice the mean gain across all groups. With no inequality aversion the aggregate gains from trade are $1.5 \%$. Nevertheless, trade increases inequality, thus lowering the inequality-adjusted gains from trade to $1.37 \%$.

Relative to the reduced-form approach in Autor et al. (2013), our general-equilibrium structural analysis enables us to compute the welfare gains and losses caused by the China shock across groups, rather than only the associated relative income effects. We can also quantify the welfare effects of counterfactual shocks such as a move to autarky or a decline in trade costs. Our framework thus serves to establish a formal connection between the fast-growing empirical literature on the distributional implications of trade shocks and the more theoretical approaches to compute aggregate welfare effects of trade surveyed in Costinot and Rodríguez-Clare (2014). At the same time, by assuming competitive labor markets with a perfectly inelastic labor supply, all welfare effects operate through changes in real factor prices. As a result, we are unable to capture the effects of trade on employment, and the large associated costs to individuals inside groups. As discussed in detail towards the end of the paper, this is an important and challenging question for future research.

Our paper is related to several research areas in international trade. A growing body of empirical work documents substantial variation in local labor-market outcomes in response to national-level trade shocks. In addition to Autor et al. (2013), see for example Dix-Carneiro and Kovak (2016), Kovak (2013) and Topalova (2010). ${ }^{4}$ Additionally, a large empirical and theoretical literature studies the distributional effects of trade some important recent contributions are Autor, Dorn, Hanson and Song (2014), Burstein and Vogel (2016), Costinot and Vogel (2010), Helpman, Itskhoki, Muendler and Redding (2017) and Krishna, Poole and Senses (2012). A literature focusing specifically on the effect of trade shocks on the reallocation of workers across sectors finds significant effects

\footnotetext{
${ }^{3}$ We discuss how to calibrate inequality aversion in Section 5. As a preview, one can assume as in Jones and Klenow (2016) that this comes from risk aversion for agents behind the veil of ignorance - in that case one can use estimates of risk aversion to calibrate inequality aversion.

${ }^{4}$ Other empirical papers exploring the effects of trade shocks on local labor markets are Dauth, Findeisen and Suedekum (2014), Hakobyan and McLaren (2016) and Yi, Müller and Stegmaier (2016)
} 
for developed countries (Artuç, Chaudhuri and McLaren 2010, Pierce and Schott 2016, Revenga 1992), although less so in developing counries (see, e.g., Goldberg and Pavcnik 2007 and Dix-Carneiro 2014).

Artuç et al. (2010), Dix-Carneiro (2014) and Adão (2016) also use a Roy model of the allocation of workers across sectors to offer a structural analysis of the distributional effects of trade shocks, but they focus on exogenous changes in the terms of trade in a small economy. ${ }^{5}$ We complement these papers by linking the Roy model of the labor market with a gravity model of trade and by using the resulting framework to provide a simple and transparent way to quantify the aggregate and distributional welfare effects of trade. In this respect, our paper is most closely related to Caliendo et al. (2015), Lee (2016), and Adao et al. (2017). All these papers develop models similar to ours but pursue different estimation methods and focus on different questions: Caliendo et al. (2015) emphasize the dynamics of adjustment after an unexpected trade shock, Lee (2016) focuses on the implications for the skill premium, and Adao et al. (2017) center on how the effect of the trade shock is affected by the interaction between workers' employment decisions and agglomeration economies at the local level. ${ }^{6}$

Finally, our paper is also related to Hsieh and Ossa (2011), who use a gravity framework to conduct a comparative-statics analysis in the style of Dekle et al. (2008) to quantify the aggregate effects of the China shock, and to Amiti, Dai, Feenstra and Romalis (2017) and Bai and Stumpner (2017), both of which estimate the effect of the China shock on the U.S. consumer price index.

The rest of this paper is structured as follows. Section 2 describes the baseline model and presents our theoretical results. The data is described in Section 3, and Section 4 discusses the empirical findings and structural estimation of the model. Section 5 presents the results of the estimated model and the calibrated China shock for welfare of US groups, while Section 6 computes the aggregate and group-level gains from trade. Section 7 presents extensions of the baseline model and a discussion of employment effects. Section 8 concludes.

\footnotetext{
${ }^{5}$ Other structural analyses of trade liberalization and labor market adjustments are Coşar (2013), Coşar, Guner and Tybout (2016) and Kambourov (2009). There is also a literature on the impact of trade on poverty and the income distribution using a Computable General Equilibrium (CGE) methodology - see for example Cockburn, Decaluwé and Robichaud (2008).

${ }^{6}$ While all the papers cited so far focus on the differential impact of trade through the earnings channel, another set of papers focuses on the expenditure channel - see Atkin and Donaldson (2015), Faber (2014), Fajgelbaum and Khandelwal (2016) and Porto (2006).
} 


\section{Theory}

We present a multi-sector, multi-country, Ricardian model of trade with heterogeneous workers. There are $N$ countries and $S$ sectors. Each sector is modeled as in Eaton and Kortum (2002) - henceforth EK; there is a continuum of goods, preferences across goods within a sector $s$ are CES with elasticity of substitution $\sigma_{s}$, and technologies have constant returns to scale with productivities that are distributed Fréchet with shape parameter $\theta_{s}>\sigma_{s}-1$ and level parameters $T_{i s}$ in country $i$ and sector $s$. Preferences across sectors are Cobb-Douglas with shares $\beta_{i s}$. There are iceberg trade $\operatorname{costs} \tau_{i j s} \geq 1$ to export goods in sector $s$ from country $i$ to country $j$, with $\tau_{i i s}=1$.

On the labor side, we assume that there are $G_{i}$ groups of workers in country $i$. A worker from group $g$ in country $i$ (henceforth simply group $i g$ ) has a number of efficiency units $z_{s}$ in sector $s$ drawn from a Fréchet distribution with shape parameter $\kappa_{i g}>1$ and scale parameters $A_{i g s}$. Thus, workers within each group are ex-ante identical but ex-post heterogeneous due to different ability draws across sectors, as in Roy (1951), while workers across groups also differ in that they draw their abilities from different distributions. The number of workers in a group is fixed and denoted by $L_{i g}$. This implies that labor supply is inelastic - workers simply choose the sector to which they supply their entire labor endowment. In Section 7 we discuss extensions that allow for endogenous labor supply arising from mobility of workers across groups or the possibility of home production.

If $\kappa_{i g} \rightarrow \infty$ for all $i g$ and $A_{i g s}=1$ for all $i g s$, the model collapses to the multi-sector EK model developed in Costinot et al. (2012), while if $\kappa_{i g} \rightarrow 1$ for all $i g$ then the model has the same welfare and counterfactual implications as the model in which labor is sector specific. ${ }^{7}$ On the other hand, if $\tau_{i j s} \rightarrow \infty$ for all $j \neq i$ and $G_{i}=1$ then economy $i$ is in autarky and collapses to the Roy model in Lagakos and Waugh (2013) (see also Hsieh et al. (2013)). ${ }^{8}$

\footnotetext{
${ }^{7}$ The only difference between the model with sector-specific labor and ours with $\kappa_{i g} \rightarrow 1$ is that in ours the elasticity of labor supply to any particular sector with respect to the wage in that sector goes to one and not zero. However, for $\kappa_{i g} \rightarrow 1$ the reallocation of workers across sectors has no effect on the relative supply of efficiency units of labor across sectors - see Equation 4 . Note that $\kappa_{i g} \rightarrow 1$ implies that $\eta_{i g} \rightarrow \infty$ - when we report results for this limit we are implicitly normalizing $E_{i g s}$ by $\eta_{i g}$.

${ }^{8}$ There are two sources of comparative advantage in this model: first, as in Costinot et al. (2012), differences in $T_{i s}$ drive sector-level (Ricardian) comparative advantage; second, differences in $A_{i g s}$ lead to factor-endowment driven comparative advantage. Given the nature of our comparative statics exercise,
} 


\subsection{Equilibrium}

To determine the equilibrium of the model, it is useful to separate the analysis into two parts: the determination of labor demand in each sector in each country as a function of wages, which comes from the EK part of the model; and the determination of labor supply to each sector in each country as a function of wages, which comes from the Roy part of the model.

Since workers are heterogeneous in their sector productivities, the supply of labor to each sector is upward sloping, and hence wages can differ across sectors. However, since technologies and goods prices are national, wages cannot differ across groups. Let wages per efficiency unit in sector $s$ of country $i$ be denoted by $w_{i s}$. From EK we know that the demand for efficiency units in sector $s$ in country $i$ is

$$
\frac{1}{w_{i s}} \sum_{j} \lambda_{i j s} \beta_{j s} X_{j},
$$

where $X_{j}$ is total expenditure by country $j$ and $\lambda_{i j s}$ are sectoral trade shares given by

$$
\lambda_{i j s}=\frac{T_{i s}\left(\tau_{i j s} w_{i s}\right)^{-\theta_{s}}}{\sum_{l} T_{l s}\left(\tau_{l j s} w_{l s}\right)^{-\theta_{s}}} .
$$

For future purposes, also note that the price index in sector $s$ in country $j$ is

$$
P_{j s}=\gamma_{s}^{-1}\left(\sum_{i} T_{i s}\left(\tau_{i j s} w_{i s}\right)^{-\theta_{s}}\right)^{-1 / \theta_{s}},
$$

where $\gamma_{s} \equiv \Gamma\left(1-\frac{\sigma_{s}-1}{\theta_{s}}\right)^{1 /\left(1-\sigma_{s}\right)}$.

Labor supply is determined by workers' choices regarding which sector to work in. Let $\boldsymbol{z}=\left(z_{1}, z_{2}, \ldots, z_{S}\right)$ and let $\Omega_{i s} \equiv\left\{\boldsymbol{z}\right.$ s.t. $w_{i s} z_{s} \geq w_{i k} z_{k}$ for all $\left.k\right\}$. A worker with productivity vector $\boldsymbol{z}$ in country $i$ will choose sector $s$ iff $\boldsymbol{z} \in \Omega_{i s}$. Let $F_{i g}(\boldsymbol{z})$ be the joint probability distribution of $\boldsymbol{z}$ for workers of group ig. From Lagakos and Waugh (2013) and Hsieh et al. (2013) we know that the share of workers in group $i g$ that choose to work in sector $s$ is: ${ }^{9}$

however, the source of comparative advantage will not matter for the results - only the actual sector-level specialization as revealed by the trade data will be relevant.

${ }^{9}$ This result and the ones below generalize easily to a setting with correlation in workers' ability draws across sectors. In this case, the dispersion parameter $\kappa_{i g}$ is replaced by $\kappa_{i g} /\left(1-\rho_{i g}\right)$, where $\rho_{i g}$ measures 


$$
\pi_{i g s} \equiv \int_{\Omega_{i s}} d F_{i g}(\boldsymbol{z})=\frac{A_{i g s} w_{i s}^{\kappa_{i g}}}{\Phi_{i g}^{\kappa_{i g}}},
$$

where $\Phi_{i g}^{\kappa_{i g}} \equiv \sum_{k} A_{i g k} w_{i k}^{\kappa_{i g}}$. In turn, the supply of efficiency units by this group to sector $s$ is given by

$$
E_{i g s} \equiv L_{i g} \int_{\Omega_{i s}} z_{s} d F_{i g}(\boldsymbol{z})=\eta_{i g} \frac{\Phi_{i g}}{w_{i s}} \pi_{i g s} L_{i g}
$$

where $\eta_{i g} \equiv \Gamma\left(1-1 / \kappa_{i g}\right)$. One implication of this result is that income levels per worker are equalized across sectors. That is, for group $i g$, we have

$$
\frac{w_{i s} E_{i g s}}{\pi_{i g s} L_{i g}}=\eta_{i g} \Phi_{i g}
$$

This is a special implication of the Fréchet distribution and it implies that the share of income obtained by workers of group $i g$ in sector $s$ (i.e., $w_{i s} E_{i g s} / \sum w_{i k} E_{i g k}$ ) is also given by $\pi_{i g s}$. Note also that total income of group $i g$ is $Y_{i g} \equiv \sum_{s} w_{i s} E_{i g s}=\eta_{i g} L_{i g} \Phi_{i g}$, while total income in country $i$ is $Y_{i} \equiv \sum_{g \in G_{i}} Y_{i g}$.

Allowing for trade imbalances $D_{j}$ via transfers as in Dekle et al. (2008), we have

$$
X_{j}=Y_{j}+D_{j}
$$

with $\sum_{j} D_{j}=0$. Finally, combining the supply and demand sides of the economy, the excess demand for efficiency units in sector $s$ of country $i$ is

$$
E L D_{i s} \equiv \frac{1}{w_{i s}} \sum_{j} \lambda_{i j s} \beta_{j s} X_{j}-\sum_{g \in G_{i}} E_{i g s} .
$$

Since $\lambda_{i j s}, Y_{j}$ and $E_{i g s}$ are functions of the whole matrix of wages $\boldsymbol{w} \equiv\left\{w_{i s}\right\}$, the system $E L D_{i s}=0$ for all $i$ and $s$ is a system of equations in $\boldsymbol{w}$ whose solution gives the equilibrium wages for some choice of numeraire.

\subsection{Comparative Statics}

Consider some change in trade costs or technology parameters. We proceed as in Dekle et al. (2008) and solve for the proportional change in the endogenous variables. For- 
mally, using notation $\hat{x} \equiv x^{\prime} / x$, we consider shocks $\hat{\tau}_{i j s}$ for $i \neq j, \hat{D}_{j}, \hat{A}_{i g s}$ and $\hat{T}_{i s}$. The counterfactual equilibrium entails $E L D_{i s}^{\prime}=0$ for all $i, s$. Noting that $w_{i s}^{\prime} E_{i g s}^{\prime}=$ $\hat{\pi}_{i g s} \hat{Y}_{i g} \pi_{i g s} Y_{i g}$, equation $E L D_{i s}^{\prime}=0$ can be written as

$$
\sum_{j} \hat{\lambda}_{i j s} \lambda_{i j s} \beta_{j s}\left(\sum_{g \in G_{j}} \hat{Y}_{j g} Y_{j g}+\hat{D}_{j} D_{j}\right)=\sum_{g \in G_{i}} \hat{\pi}_{i g s} \hat{Y}_{i g} \pi_{i g s} Y_{i g}
$$

with

$$
\begin{aligned}
& \hat{Y}_{i g}=\left(\sum_{k} \pi_{i g k} \hat{A}_{i g k} \hat{w}_{i k}^{\kappa_{i g}}\right)^{1 / \kappa_{i g}}, \\
& \hat{\lambda}_{i j s}=\frac{\hat{T}_{i s}\left(\hat{\tau}_{i j s} \hat{w}_{i s}\right)^{-\theta_{s}}}{\sum_{k} \lambda_{k j s} \hat{T}_{k s}\left(\hat{\tau}_{k j s} \hat{w}_{k s}\right)^{-\theta_{s}}},
\end{aligned}
$$

and

$$
\hat{\pi}_{i g s}=\frac{\hat{A}_{i g s} \hat{w}_{i s}^{\kappa_{i g}}}{\sum_{k} \pi_{i g k} \hat{A}_{i g k} \hat{w}_{i k}^{\kappa_{i g}}} .
$$

Given values for parameters $\theta_{s}$ and $\kappa_{i g}$; data on income levels, $Y_{i g}$, trade imbalances, $D_{j}$, trade shares, $\lambda_{i j s}$, expenditure shares, $\beta_{i s}$, labor allocation shares $\pi_{i g s}$, and labor endowments, $L_{i g}$; and the shocks to trade costs, $\hat{\tau}_{i j s}$, trade imbalances, $\hat{D}_{j}$, and productivity levels, $\hat{A}_{i g s}$ and $\hat{T}_{i s}$, we can solve for changes in wages, $\hat{w}_{i s}$, from the system of equations associated with (7)-(10), and then solve for all other relevant changes, including changes in trade shares using (9) and changes in employment shares using (10).

\subsection{Group-Level Welfare Effects}

Our measure of welfare of individuals in group $i g$ is ex-ante real income, $W_{i g} \equiv \frac{Y_{i g} / L_{i g}}{P_{i}}$. We are interested in the change in $W_{i g}$ caused by a shock to trade costs or foreign technology levels, henceforth simply referred to as a "foreign shock." Cobb-Douglas preferences imply that

$$
\hat{W}_{i g}=\hat{Y}_{i g} \prod_{s} \hat{P}_{i s}^{-\beta_{i s}}
$$

From (2) and (9) and given $\hat{T}_{i s}=1$ for all $s$ in domestic country $i$, we have $\hat{P}_{i s}=\hat{w}_{i s} \hat{\lambda}_{i i s}^{1 / \theta_{s}}$ while from (8) and (10) we have $\hat{Y}_{i g}=\hat{w}_{i s} \hat{\pi}_{i g s}^{-1 / \kappa_{i g}}$. Combining these two results with (11) we arrive at the following proposition:

Proposition 1. Given some shock to trade costs or foreign technology levels, the ex-ante 
percentage change in the real wage of group $g$ in country $i$ is given by

$$
\hat{W}_{i g}=\prod_{s} \hat{\lambda}_{i i s}^{-\beta_{i s} / \theta_{s}} \cdot \prod_{s} \hat{\pi}_{i g s}^{-\beta_{i s} / \kappa_{i g}}
$$

The RHS of the expression in (12) has two components: $\prod_{s} \hat{\lambda}_{i i s}^{-\beta_{i s} / \theta_{s}}$ and $\prod_{s} \hat{\pi}_{i g s}^{-\beta_{i s} / \kappa_{i g}}$, with all variation across groups coming from the second term. If $\kappa_{i g} \longrightarrow \infty$ for all $g \in G_{i}$ then the gains for all groups in country $i$ are equal to $\prod_{s} \hat{\lambda}_{i i s}^{-\beta_{i s} / \theta_{s}}$, which is the multisector formula for the welfare effect of a trade shock in ACR. It is easy to show that the term $\prod_{s} \hat{\lambda}_{i i s}^{-\beta_{i s} / \theta_{s}}$ corresponds to the change in real income given wages while the term $\prod_{s} \hat{\pi}_{i g s}^{-\beta_{i s} / \kappa_{i g}}$ corresponds to the change in real income for group $i g$ coming exclusively from changes in wages $\hat{w}_{i s}$ for $s=1, \ldots, S{ }^{10}$

The term $\prod_{s} \hat{\pi}_{i g s}^{-\beta_{i s} / \kappa_{i g}}$ is related to the change in the degree of specialization of group $i g$. We use the Kullback-Leibler (KL) divergence as a way to define the degree of specialization of a group. Formally, the KL divergence of $\boldsymbol{\pi}_{i g} \equiv\left\{\pi_{i g 1}, \pi_{i g 2}, \ldots, \pi_{i g S}\right\}$ from $\boldsymbol{\beta}_{i} \equiv\left\{\beta_{i 1}, \beta_{i 2}, \ldots, \beta_{i S}\right\}$ is given by

$$
D_{K L}\left(\boldsymbol{\pi}_{i g} \| \boldsymbol{\beta}_{i}\right) \equiv \sum_{s} \beta_{i s} \ln \left(\beta_{i s} / \pi_{i g s}\right) .
$$

Note that if group ig was in full group-level autarky (i.e., not trading with any other group or country) then $\pi_{i g s}=\beta_{i s}$. Thus, $D_{K L}\left(\boldsymbol{\pi}_{i g} \| \boldsymbol{\beta}_{i}\right)$ is a measure of the degree of specialization as reflected in the divergence of the actual distribution $\boldsymbol{\pi}_{i g}$ relative to $\boldsymbol{\beta}_{i}$. We can now write

$$
\prod_{s} \hat{\pi}_{i g s}^{-\beta_{i s} / \kappa_{i g}}=\exp \left(\frac{1}{\kappa_{i g}}\left[D_{K L}\left(\boldsymbol{\pi}_{i g}^{\prime} \| \boldsymbol{\beta}_{i}\right)-D_{K L}\left(\boldsymbol{\pi}_{i g} \| \boldsymbol{\beta}_{i}\right)\right]\right)
$$

\footnotetext{
${ }^{10}$ The result in Proposition 1 can alternatively be derived by first applying the envelope theorem to the consumption and labor allocation problem at the group level,

$$
d \ln W_{j g}=\sum_{s} \pi_{j g s} d \ln w_{j s}-\sum_{i, s} \beta_{j s} \lambda_{i j s} d \ln \left(w_{i s} \tau_{i j s}\right) .
$$

We can then proceed as in ACR to substitute for $d \ln w_{j s}$ and $d \ln \left(w_{i s} \tau_{i j s}\right)$ in this expression. From the trade side of the model we have $\frac{d \ln \left(\lambda_{i j s} / \lambda_{j j s}\right)}{d \ln \left(w_{i s} \tau_{i j s} / w_{j s}\right)}=-\theta_{s}$, while from the labor side we have $\frac{d \ln \left(\pi_{j g s} / \pi_{j g k}\right)}{d \ln \left(w_{j s} / w_{j k}\right)}=-\kappa_{j g}$. Solving for $d \ln \left(w_{i s} \tau_{i j s}\right)$ and $d \ln w_{j s}$ from these two equations, respectively, and then plugging back into the expression for $d \ln W_{j g}$ above yields $d \ln W_{j g}=-\sum_{s} \beta_{j s}\left[\frac{d \ln \pi_{j g s}}{\kappa_{j g}}+\frac{d \ln \lambda_{j j s}}{\theta_{s}}\right]$. Integration leads to the result in (12).
} 
This implies that, apart from the common term $\prod_{s} \hat{\lambda}_{i i s}^{-\beta_{i s} / \theta_{s}}$, the welfare effect of a trade shock on a particular group in country $i$ is determined by the change in the degree of specialization of that group as measured by the KL divergence, multiplied by the degree of heterogeneity in worker productivity across sectors as captured by $1 / \kappa_{i g}$. For example, a group that with high employment in textiles would become less specialized and gain less from trade (compared to other groups) if a foreign shock leads the country to import disproportionally more textiles.

As a parenthesis, we comment briefly on how our model relates to the one in $\mathrm{ADH}$. They derive their regression equations from a log-linear approximation of the equilibrium conditions of a multi-sector gravity model of trade with homogeneous and perfectly mobile workers across sectors, but with each group modeled as a separate economy. In this case all the variation in the effects of a shock across groups arises because of different terms of trade effects. In our baseline model technologies are national and there are no trade costs among groups within countries, so terms of trade are the same for all groups. Instead, worker heterogeneity implies that some groups of workers are more closely attached to some sectors, and it is this that generates variation in the effect of trade shocks across groups.

\subsection{Aggregate Welfare Effects}

The aggregate welfare effect can be obtained from Proposition 1 as $\hat{W}_{i} \equiv \hat{Y}_{i} / \hat{P}_{i}=$ $\sum_{g \in G_{i}}\left(Y_{i g} / Y_{i}\right) \hat{W}_{i g}$. Using (12), this can be written explicitly as

$$
\hat{W}_{i}=\prod_{s} \hat{\lambda}_{i i s}^{-\beta_{i s} / \theta_{s}} \cdot \sum_{g \in G_{i}}\left(\frac{Y_{i g}}{Y_{i}}\right) \prod_{s} \hat{\pi}_{i g s}^{-\beta_{i s} / \kappa_{i g}} .
$$

The aggregate welfare effect of a trade shock is no longer given by the multi-sector ACR term (i.e., $\hat{W}_{i} \neq \prod_{s} \hat{\lambda}_{i i s}^{-\beta_{i s} / \theta_{s}}$ ). This is because a trade shock will in general affect wages $w_{i s}$, and this in turn will affect welfare through its impact on income and sector-level prices.

\subsection{Aggregate and Group-Level Gains from Trade}

Following ACR, we define the gains from trade as the negative of the proportional change in real income for a shock that takes the economy back to autarky: $G T_{i} \equiv 1-\hat{W}_{i}^{A}$ and 
$G T_{i g} \equiv 1-\hat{W}_{i g}^{A}$. A move to autarky for country $i$ entails $\hat{\tau}_{i j s}=\infty$ for all $s$ and all $i \neq j$ and $\hat{D}_{i}=0$. Conveniently, solving for changes in wages in country $i$ (i.e., solving for $\hat{w}_{i s}$ for $s=1, \ldots, S$ ) from Equation (7) only requires knowing the values of employment shares, income levels and expenditure shares for country $i$, namely $\beta_{i s}$ for all $s$ and $\pi_{i g s}$ and $Y_{i g}$ for all $g, s$. This can be seen by letting $\hat{\tau}_{i j s} \rightarrow \infty$ in Equation (7), which yields

$$
\beta_{i s} \sum_{g \in G_{i}} \hat{Y}_{i g} Y_{i g}=\sum_{g \in G_{i}} \hat{\pi}_{i g s} \hat{Y}_{i g} \pi_{i g s} Y_{i g}
$$

Let $r_{i s} \equiv \sum_{g \in G_{i}} \pi_{i g s} Y_{i g} / Y_{i}$ be the share of sector $s$ in total output in country $i$ and note that country $i$ engages in inter-industry trade as long as $r_{i s} \neq \beta_{\text {is }}$ for some $s$.

Proposition 2. Assume that $\kappa_{i g}=\kappa_{i}$ for all $g \in G_{i}$. If $\kappa_{i}<\infty$ and country $i$ engages in inter-industry trade, then the aggregate gains from trade are strictly higher than those that arise in the limit as $\kappa_{i} \longrightarrow \infty$.

Appendix C has the proof. To understand this result, it is useful to consider the simpler case with a single group of workers, $G_{i}=1$. In this case, a move back to autarky would imply

$$
\hat{W}_{i}^{A}=\prod_{s} \lambda_{i i s}^{\beta_{i s} / \theta_{s}} \cdot \exp \left[-\frac{1}{\kappa_{i}} D_{K L}\left(\boldsymbol{r}_{i} \| \boldsymbol{\beta}_{i}\right)\right]
$$

If there is inter-industry trade then $D_{K L}\left(\boldsymbol{r}_{i} \| \boldsymbol{\beta}_{i}\right)>0$ so (given $\boldsymbol{r}_{i}$ ) a finite $\kappa_{i}$ implies a lower $\hat{W}_{i}{ }^{A}$ than in the multi-sector ACR formula. Intuitively, a finite $\kappa_{i}$ introduces more "curvature" to the PPF, making it harder for the economy to adjust as it moves to autarky. This implies higher losses if the economy were to move to autarky, and hence higher gains from trade. Proposition 2 establishes that this result generalizes to the case $G_{i}>1$.

Turning to the group-specific gains from trade, we again use the KL measure of specialization to understand whether a group gains more or less than the economy as a whole. The results of the previous section imply that the gains from trade for group $i g$ are

$$
G T_{i g}=1-\prod_{s} \lambda_{i i s}^{\beta_{i s} / \theta_{s}} \cdot \exp \left(\frac{1}{\kappa_{i g}}\left[D_{K L}\left(\boldsymbol{\pi}_{i g}^{A} \| \boldsymbol{\beta}_{i}\right)-D_{K L}\left(\boldsymbol{\pi}_{i g} \| \boldsymbol{\beta}_{i}\right)\right]\right)
$$

The term $D_{K L}\left(\boldsymbol{\pi}_{i g}^{A} \| \boldsymbol{\beta}_{i}\right)-D_{K L}\left(\boldsymbol{\pi}_{i g} \| \boldsymbol{\beta}_{i}\right)$ could be positive or negative, depending on whether group $i g$ becomes more or less specialized with trade as measured by the KL 
divergence.

Consider a group $i g$ that happens to have efficiency parameters $\left(A_{i g 1}, \ldots, A_{i g S}\right)$ that give it a strong comparative advantage in a sector $s$ for which the country as a whole has a comparative disadvantage, as reflected in positive net imports in that sector. Group $i g$ would be highly specialized in $s$ when the country is in autarky (but groups trade among themselves) but that specialization would diminish as the country starts trading with the rest of the world. As a consequence, the KL degree of specialization falls with trade for group $i g$, implying lower gains relative to other groups in the economy.

\subsection{A Bartik Approximation}

Focusing on the implications of a foreign shock on a group's relative income, equation (8) implies that

$$
\frac{\hat{Y}_{i g}}{\hat{Y}_{i}}=\left(\sum_{s} \pi_{i g s}\left(\frac{\hat{w}_{i s}}{\hat{Y}_{i}}\right)^{\kappa_{i g}}\right)^{1 / \kappa_{i g}} .
$$

Since wages are not observable, it is convenient to derive an approximation for this expression that uses changes in output shares, $\hat{r}_{i s}$ rather than $\hat{w}_{i s}$. Assuming that $\kappa_{i g}=$ $\kappa_{i}$ for all $g \in G_{i}$ and recalling that $r_{i s} \equiv \sum_{g \in G_{i}} \pi_{i g s} Y_{i g} / Y_{i}$, equations (8) and (10) imply:

$$
\hat{r}_{i s}=\sum_{g \in G_{i}} \frac{\left(Y_{i g} / Y_{i}\right) \pi_{i g s}}{r_{i s}}\left(\frac{\hat{Y}_{i g}}{\hat{Y}_{i}}\right) \hat{\pi}_{i g s}=\left(\frac{\hat{w}_{i s}}{\hat{Y}_{i}}\right)^{\kappa_{i}} \sum_{g \in G_{i}} \frac{\left(Y_{i g} / Y_{i}\right) \pi_{i g s}}{r_{i s}}\left(\frac{\hat{Y}_{i g}}{\hat{Y}_{i}}\right)^{1-\kappa_{i}} .
$$

The term $\frac{\left(Y_{i g} / Y_{i}\right) \pi_{i g s}}{r_{i s}}$ captures group ig's share of country $i$ 's total output of sector $s$, and $\left(\hat{Y}_{i g} / \hat{Y}_{i}\right)^{1-\kappa_{i}}$ is an adjustment to take into account how $\left(\hat{Y}_{i g} / \hat{Y}_{i}\right) \hat{\pi}_{i g s}$ deviates from $\left(\hat{w}_{i s} / \hat{Y}_{i}\right)^{\kappa_{i}}$ for group $i g$. The sum on the RHS of the previous equation is then an overall adjustment for how $\hat{r}_{i s}$ may deviate from $\left(\hat{w}_{i s} / \hat{Y}_{i}\right)^{\kappa_{i}}$. For $\kappa$ close to 1 or for shocks that do not lead to large differences in $\hat{Y}_{i g} / \hat{Y}_{i}$ from 1 for groups with large weights in sector $s$, that adjustment will be small, and $\hat{r}_{i k} \approx\left(\hat{w}_{i s} / \hat{Y}_{i}\right)^{\kappa_{i}}$, implying that

$$
\frac{\hat{Y}_{i g}}{\hat{Y}_{i}} \approx\left(\sum_{k} \pi_{i g k} \hat{r}_{i k}\right)^{1 / \kappa_{i}}
$$

In the quantitative analysis in Sections 5 and 6 we will see that this equation provides a very good approximation of the model implied group-level relative income effects of 
the China shock and the move back to autarky for the United States. The benefit of this result is that $\hat{r}_{i s}$ is observable in the data. Thus, if we can identify the impact of a foreign shock on output shares, then we can use this Bartik-style result to compute approximate relative income changes across groups.

This result is particularly useful for the shock that takes country $i$ back to autarky. For that case we have $\hat{r}_{i s}=\beta_{i s} / r_{i s}$ and hence we obtain an approximate sufficient statistic for a group's gains from trade relative to the aggregate gains:

$$
\frac{\hat{Y}_{i g}^{A}}{\hat{Y}_{i}^{A}} \approx I_{i g}^{1 / \kappa_{i}} \equiv\left(\sum_{s} \pi_{i g s} \frac{\beta_{i s}}{r_{i s}}\right)^{1 / \kappa_{i}} .
$$

We can think of $\beta_{i s} / r_{i s}$ as an index of the degree of import competition in industry $s$ and $I_{i g}$ as an index of import competition faced by group $g$. Thus, for a move back to autarky, the change in relative income levels across groups is approximated by the index of import competition that we can directly observe in the data elevated to the power $1 / \kappa_{i}$. Note also that, since a foreign shock does not affect the autarky equilibrium, we can use the result in (16) to rewrite the approximation in (15) for any foreign shock in terms of the change in the index of import competition, $\frac{\hat{Y}_{i g}}{\hat{Y}_{i}} \approx \hat{I}_{i g}^{-1 / \kappa_{i}}$.

\subsection{Inequality-Adjusted Welfare Effects}

We follow Atkinson (1970) and think about social welfare as a (geometric) average of welfare across all individuals with a constant inequality aversion parameter $\rho>0$ (with $\rho \neq 1$ to simplify the exposition below). Since the $z_{s}$ for workers in group $i g$ is distributed Frechet with scale parameter $A_{i g s}$ and shape parameter $\kappa_{i g}$, then income $\max _{s} w_{i s} z_{s}$ for workers in group $i g$ is distributed Frechet with scale parameter $\Phi_{i g}^{\kappa_{i g}}$ and shape parameter $\kappa_{i g}$. Social welfare in country $i$ is then:

$$
U_{i}=\left(\sum_{g \in G_{i}} \frac{\Gamma\left(1-\frac{1-\rho}{\kappa_{i g}}\right)}{\eta_{i g}^{1-\rho}} l_{i g} W_{i g}^{1-\rho}\right)^{\frac{1}{1-\rho}}
$$


where $l_{i g} \equiv L_{i g} / L_{i} .{ }^{11}$ There are different interpretations of this social welfare function, but since this is relevant for the calibration of the parameter $\rho$, we postpone this discussion until Section 5.

In the quantitative section below we will focus on the case $\kappa_{i g}=\kappa_{i}$, which implies that

$$
U_{i}=\tilde{\eta}_{i}\left(\sum_{g} l_{i g} W_{i g}^{1-\rho}\right)^{\frac{1}{1-\rho}}
$$

where $\tilde{\eta}_{i} \equiv \frac{\Gamma\left(1-\frac{1-\rho}{\kappa_{i}}\right)^{\frac{1}{1-\rho}}}{\Gamma\left(1-\frac{1}{\kappa_{i}}\right)}$. The inequality-adjusted welfare effect of a foreign shock is defined as $\hat{U}_{i}-1$ whereas the inequality-adjusted gains from trade are defined as $I G T_{i} \equiv$ $1-\hat{U}_{i}^{A}$. If $\rho=0$ then these measures correspond to those defined above, namely $\hat{W}_{i}-1$ and $G T_{i} \equiv 1-\hat{W}_{i}^{A} \cdot{ }^{12}$

To write these results in terms of observables and the endogenous group-level welfare changes $\hat{W}_{i g}$, let $\omega_{i g} \equiv \frac{l_{i g}\left(Y_{i g} / L_{i g}\right)^{1-\rho}}{\sum_{h} l_{i h}\left(Y_{i h} / L_{i h}\right)^{1-\rho}}$ be a modified weight for group $i g$ in country $i$ welfare that appropriately accounts for the social value of income accruing to groups with different income levels. Then simple algebra reveals that

$$
\hat{U}_{i}=\left(\sum_{g} \omega_{i g} \hat{W}_{i g}^{1-\rho}\right)^{\frac{1}{1-\rho}}
$$

\section{Data}

For our quantitative analysis, we define groups based on geographic location and education. We follow ADH in using commuting zones (CZs) as geographic units to define local labor markets, and further separate each CZ into two groups based on whether workers hold at least an Associate's degree. ${ }^{13}$ This leaves us with a total of 1,444 groups

\footnotetext{
${ }^{11}$ This result is derived by integrating $U_{i}=\frac{1}{P_{i} L_{i}}\left(\sum_{g \in G_{i}} \int_{0}^{\infty} y^{1-\rho} L_{i g} d H_{i g}(y)\right)^{\frac{1}{1-\rho}}$, with $H_{i g}(y)=$ $\exp \left(-\Phi_{i g}^{\kappa_{i g}} y^{-\kappa_{i g}}\right)$.

${ }^{12} \mathrm{~A}$ Rawlsian approach to social welfare entails $\rho \rightarrow \infty$ and $\hat{U}_{i}=\min _{g} W_{i g}^{\prime} / \min _{g} W_{i g}$. If $\arg \min _{g} W_{i g}^{\prime}=$ $\arg \min _{g} W_{i g}=h$ then $\hat{U}_{i}=\hat{W}_{i h}$, but of course this need not be the case.

${ }^{13}$ Our assumption of fixed groups applied to this setting implies no mobility across local labor markets and education categories. We view this as a reasonable assumption in light of existing literature that finds little evidence of trade exposure causing population shifts across local labor markets. See, for example, ADH for the US, Dauth et al. (2014) for Germany, and Dix-Carneiro and Kovak (2016) for Brazil. Moreover, except for the very long run, it seems reasonable to ignore the effect of trade on workers acquiring an Associate's degree.
} 
(722 CZs x 2 skill groups). All countries other than the US are assumed to have a single group.

Our sectors, listed in Appendix Table A.1, are based on the 1987 SIC classification codes. We aggregate all manufacturing industries into 13 sectors which roughly correspond to two-digit ISIC Rev. 3 codes. The remaining sectors, excluding public administration and the non-profit sector, are aggregated to one non-manufacturing sector.

We restrict our analysis to the period 2000-2011. We obtain national figures on bilateral trade flows, sectoral output and employment shares from the World Input-Output Database (WIOD), discussed in Timmer, Dietzenbacher, Los, Stehrer and Vries (2015). For wages and labor shares across our US groups, we rely on data from the 2000 Census and American Community Survey (ACS). ${ }^{14}$ In the regression analysis, we define labor shares $\pi_{i g s}$ based on the share of workers, share of labor hours or share of earnings in sector $s .{ }^{15}$ For the simulation analysis, we require consistency between the trade and labor data and therefore focus on $\pi_{i g s}$ as shares of earnings, $\pi_{i g s}=\frac{Y_{i g s}}{\sum_{k} Y_{i g k}}$. For US groups we also set $Y_{i g s}=\frac{Y_{i g s}^{A C S}}{\sum_{h} Y_{i h s}^{A C S}} Y_{i s}^{W I O D}$, where the superscript denotes the data source. $^{16}$

Appendix B describes in detail the construction of our dataset and the definition of our variables. It also details the supplementary data employed in our model extensions and robustness tests.

\section{Empirics}

In this section we first apply the ADH "China shock" to our setting, and examine the reduced-form impact of the China shock on income and on the share of workers employed in non-manufacturing, both at the group level. We then impose $\kappa_{i g}=\kappa$ and estimate $\kappa$ by exploiting the theoretical link between trade-induced expansion of the non-manufacturing sector and changes in group-level income. ${ }^{17}$

\footnotetext{
${ }^{14}$ The Census and ACS Public Use Microdata Areas (PUMAs) are mapped into commuting zones using a crosswalk provided by David Dorn.

${ }^{15}$ Recall that in our Roy-Frechet framework the share of workers of any group $\mathrm{ig}$ in sector $s$ is the same as the share of earnings derived from working in that sector

${ }^{16}$ The different measures for $\pi_{i g s}$ and $y_{g}$ employed in the regression and simulation analysis are highly correlated (see Figures B.1 and B.2 in the Appendix).

${ }^{17}$ Throughout the regression analysis, we restrict our sample to full-time workers. We performed a robustness analysis for the full sample of workers and find that the results are highly similar.
} 


\subsection{The rise of China as a trade shock}

Throughout our empirical analysis, we follow ADH and focus on the "China shock" to US manufacturing. Specifically, we use changes in sector-level exports from China to a group of countries similar to the US to proxy for changes in sectoral import-competition from China in the US. ${ }^{18}$ The assumption behind this identification strategy is that increased Chinese exports to these other advanced economies are driven by the exogenous "rise of China," which consists of Chinese productivity growth in manufacturing and reductions in export costs for Chinese producers. ${ }^{19}$

Our specific measure of the China import-penetration shock in sector $s$ is

$$
\Delta I P_{s t}^{C h i n a \rightarrow \text { Other }} \equiv \frac{\Delta M_{s t}^{C h i n a} \rightarrow \text { Other }}{L_{s t_{0}}^{U S}},
$$

where $L_{s t_{0}}^{U S}$ denotes US employment in sector $s$ in year 2000, $M_{s t}^{\text {China } \rightarrow \text { Other }}$ are imports from China by the above-defined set of countries for year $t$, and $\Delta$ refers to the change over the period 2000 to $2011 .^{20}$ Since we use this same period in all the regressions below, we henceforth suppress the $t$ subindex.

\subsection{Reduced-form impact of the China shock}

We first explore the impact of the China shock in our setting by examining its reducedform effect on group-level income via the following Bartik-style regression:

$$
\ln \hat{y}_{g}=\alpha+\beta \sum_{s \in M} \pi_{g s}^{M} \Delta I P_{s}^{C h i n a} \rightarrow \text { Other }+\varepsilon_{g},
$$

where $y_{g} \equiv Y_{g} / L_{g}$ is average labor income in group $g$ across all employed workers and $\pi_{g s}^{M} \equiv \pi_{g s} / \pi_{g M}$ is the share of labor employed in manufacturing sector $s$ relative to total

\footnotetext{
${ }^{18}$ This set of countries consists of Australia, Denmark, Finland, Germany, Japan and Spain. Except for Switzerland and New Zealand, which are not included in the WIOD data, this set of "Other" countries is identical to the set in ADH. Countries are selected based on having a similar income level as the US, but direct neighbors are excluded.

${ }^{19}$ For an extensive discussion on the exogeneity restrictions and the robustness of this identification strategy, see $\mathrm{ADH}$.

${ }^{20}$ Our version of the import-penetration shock differs from the one in ADH due to different sector definitions and a different time period. We chose to have more aggregated sectors in order to link the labor data with WIOD figures in a consistent manner. This is important for the simulation exercises. Compared to the ADH time period (1990-2007), our choice of time horizon (2000-2011) resulted from the constraints imposed by our different trade and labor datasets.
} 
manufacturing employment. The set of manufacturing sectors is denoted by $M$. We have suppressed the $i$ subindex as all regressions in this section are for $i=U S$.

We also check the impact of the China shock on the change in the share of employment in the non-manufacturing sector, denoted by $\pi_{g N}$. Trade-induced changes in $\pi_{g N M}$ are closely related to the $\mathrm{ADH}$ analysis, and will be central to our structural estimation of $\kappa_{U S}$. In the reduced-form regression analysis, we update equation (19) to have $\ln \hat{\pi}_{g N M}$ as the dependent variable. Throughout the entire regression analysis, we will report Conley (1999) standard errors, to account for spatial correlation in the error term. $^{21}$

In the data, we find that higher exposure to the China shock negatively affects groups' income, and leads to an expansion of the non-manufacturing sector (Table 1). ${ }^{22}$ The estimate of -0.0025 in column 1 indicates that each increase in exposure of $\$ 1,000$ per worker leads to a 0.25 percentage point smaller earnings increase. Since the difference in the change in exposure between groups at the 10th and 90th percentiles was $\$ 10,000$ per worker, this means that a group at the 90th percentile experienced a 2.5 percentage point larger earnings loss (or smaller earnings growth) than a group at the 10th percentile. For non-manufacturing employment, the estimate of 0.005 implies that a group at the 90th percentile of the exposure distribution experienced a 5 percentage point larger increase in the non-manufacturing share of employment than a group at the 10th percentile. In the next subsection, we will integrate these reduced-form findings into our structural estimation of $\kappa$.

Despite slight differences in the time period, the definition of sectors, and the countries used for the construction of the instrumental variable, our results are consistent with those in $\mathrm{ADH}$. In particular, we find that groups facing a higher exposure to the China shock experience a relative decline in average earnings and in the share of employment in manufacturing. One difference is that in $\mathrm{ADH}$ the decline in the share of employment in manufacturing comes mostly from a decline in overall manufacturing employment that is not compensated by an expansion of the non-manufacturing

\footnotetext{
${ }^{21}$ For the OLS regressions we use code from Hsiang (2010), and for the IV the original code from Conley (1999). For our baseline analysis we impose a distance cutoff for spatial correlation at $400 \mathrm{~km}$. As a robustness check, we increased the cutoff to $1000 \mathrm{~km}$ and standard errors typically increase by less than 25 percent.

${ }^{22}$ In addition, we estimate equation (19) with the group-level average labor income among workers employed in the manufacturing sector as dependent variable. We also find a negative effect, but it is not statistically significant.
} 
Table 1: Reduced-form impact of the rise of China

(a) Dependent variable: $\ln \hat{y}_{g}$

\begin{tabular}{lccc}
\hline \hline & $(1)$ & $(2)$ & $(3)$ \\
Definition of $\pi_{g s}$ & Workers & Hours & Earnings \\
\hline \hline$\sum_{s \in M} \pi_{g s}^{M} \Delta I P_{s t}^{C h i n a \rightarrow \text { Other }}$ & -0.00248 & -0.00548 & -0.000976 \\
& $(0.00116)$ & $(0.00251)$ & $(0.000474)$ \\
\hline Observations & 1444 & 1444 & 1444 \\
\hline \hline
\end{tabular}

(b) Dependent variable: $\ln \hat{\pi}_{g N M}$

\begin{tabular}{lccc}
\hline \hline & $\begin{array}{c}(1) \\
\text { Workers }\end{array}$ & $\begin{array}{c}(2) \\
\text { Hours }\end{array}$ & $\begin{array}{c}(3) \\
\text { Earnings }\end{array}$ \\
\hline \hline$\sum_{s \in M} \pi_{g s}^{M} \Delta I P_{s t}^{C h i n a} \rightarrow$ Other & 0.00532 & 0.0111 & 0.00191 \\
& $(0.00110)$ & $(0.00245)$ & $(0.000606)$ \\
\hline Observations & 1444 & 1444 & 1444 \\
\hline \hline
\end{tabular}

Estimation results for specification (19), where $\ln \hat{y}_{g}$, the dependent variable in panel (a), is measured as the log change in the average earnings per worker. The dependent variable in panel (b) is $\ln \hat{\pi}_{g N M}$, the $\log$ change in the labor share of the non-manufacturing sector. Labor shares $\pi_{g s}$ are measured as the share of workers, share of labor hours and share of earnings for columns 1, 2 and 3 respectively. China shock exposure measured in $\$ 1,000$ 's. Standard errors (in parentheses) are calculated as in Conley (1999), with a cutoff for the spatial correlation at $400 \mathrm{~km}$.

sector. In our case, we have focused on the manufacturing employment share while ignoring the effects on total employment - we return to this issue in Section 7.3.

\subsection{Estimation of $\kappa$}

As is evident from equation (12), the $\kappa$ parameter is central to our model as it jointly affects the aggregate and the distributional welfare effects from trade. In this subsection we estimate $\kappa$ by exploiting the relationship between trade-induced expansion of the non-manufacturing sector and income changes across groups.

Imposing $\kappa_{i g}=\kappa$ and using $\hat{y}_{g}=\hat{\Phi}_{g}$ together with equations (8) and (10) implies that $\hat{y}_{g}=\hat{A}_{g s}^{1 / \kappa} \hat{w}_{s} \hat{\pi}_{g s}^{-1 / \kappa}$. Since this holds for all sectors, we can focus on reallocation to 
non-manufacturing, which is where we know from the previous section that the China shock offers a strong instrument. After taking logs, we obtain:

$$
\ln \hat{y}_{g}=\ln \hat{w}_{N M}-\frac{1}{\kappa} \ln \hat{\pi}_{g N M}+\ln \hat{A}_{g N M}^{1 / \kappa}
$$

This gives rise to the following regression equation:

$$
\ln \hat{y}_{g}=\alpha+\beta \ln \hat{\pi}_{g N M}+\varepsilon_{g}
$$

Because our theory implies that the error term is correlated with the regressor, we instrument $\ln \hat{\pi}_{g N M}$ with the China shock variable $Z_{g} \equiv \sum_{s \in M} \pi_{g s}^{M} \Delta I P_{s}^{\text {China } \rightarrow \text { Other }}$. The exclusion restriction $E\left[\varepsilon_{g} Z_{g}\right]=0$ is satisfied as long as $E\left[\hat{A}_{g N M} \pi_{g s}^{M}\right]=0$ and $E\left[\hat{A}_{g N M} \Delta I P_{s}^{C h i n a} \rightarrow\right.$ Other $]=0$ for all $g$ and $s \in M$.

Table 2 presents the results for the IV regression described above. The first row shows our second-stage results, while the third row has the corresponding estimate $\hat{\kappa}=$ $-1 / \hat{\beta}$, and the fifth row displays the F-statistic from the first stage. As implied by our reduced-form results for the impact of the China shock on the expansion of the nonmanufacturing sector, the first-stage F-statistics are sufficiently high. The second stage estimate is always significantly different from zero, and the values for $\hat{\kappa}$ range from 1.95 to $2.15 .^{23}$ This range of values is consistent with estimates of sector/occupation employment elasticities obtained by Adao et al. (2017), for sectors, and Hsieh et al. (2013) and Burstein et al. (2015), for occupations. Despite different modeling and estimation approaches, these papers find parameters of sector/occupation productivity dispersion (analogous to our $\kappa$ ) between 1.1 and 2.2.

For the next section, where we will run simulations to analyze the quantitative role of $\kappa$ in our framework, we will set our preferred value at $\kappa=2$. In addition, we will also show results for $\kappa \rightarrow 1$ (the theoretical lower bound for $\kappa$ ), and for $\kappa=4$. The latter value is an upper bound of the $95 \%$ confidence intervals for the $\kappa$ estimates.

\footnotetext{
${ }^{23}$ As a robustness check, we also estimate $\kappa$ on a sample including part-time workers and find slightly lower point estimates, with values centered around $\kappa=1.6$ (see Appendix Table A.2). These values are within the $95 \%$ confidence intervals of the estimations in the current table, but would imply stronger distributional effects from the China shock. We also examined heterogeneity in kappa values for low versus high-educated groups, and found that the kappa for high-educated workers is lower, but not significantly different from the kappa for low-educated workers.
} 
Table 2: Estimation of $\kappa$

\begin{tabular}{lccc}
\hline \hline & \multicolumn{3}{c}{ Dependent variable: $\ln \hat{y}_{g}$} \\
Definition of $\pi_{g s}$ & Workers & Hours & Earnings \\
\hline \hline $\ln \hat{\pi}_{g N M}$ & -0.466 & -0.494 & -0.512 \\
& $(0.161)$ & $(0.166)$ & $(0.181)$ \\
\hline Implied $\kappa$ & 2.147 & 2.024 & 1.952 \\
& $(0.743)$ & $(0.682)$ & $(0.689)$ \\
First-stage F-Statistic & 23.19 & 20.43 & 9.902 \\
Observations & 1444 & 1444 & 1444 \\
\hline \hline
\end{tabular}

IV-estimation results for specification (20), where $y_{g}$ is average earnings per worker, and $\pi_{g N M}$ is the labor share employed in non-manufacturing. Labor shares $\pi_{g s}$ are measured as the share of workers, share of labor hours and share of earnings for columns 1, 2 and 3 respectively. Standard errors (in parentheses) are calculated as in Conley (1999), with a cutoff for the spatial correlation at approximately $400 \mathrm{~km}$. The first row shows the second-stage results, while the fourth row has the corresponding $\kappa$ estimates implied by the model and the sixth row displays the F-statistic from the first stage.

\section{Aggregate and distributional effects of the rise of China}

While existing research (e.g. ADH) has found strong distributional implications of the "rise of China" across local labor markets in the US, this empirical research remains largely silent on the associated group-level and aggregate welfare effects. We now perform counterfactual simulations with our model to shed light on this question. ${ }^{24}$

\subsection{Calibrating the China shock}

We model the rise of China as sector-specific technology shocks, $\hat{T}_{C h i n a, s}$. We calibrate these shocks such that for each sector, the simulated changes in US expenditure shares on Chinese goods match the change in these expenditure shares that is driven by the

\footnotetext{
${ }^{24}$ In all the ensuing counterfactual exercises, we follow Head and Mayer (2014) and set $\theta_{s}=5$ for all $s$. We perform our counterfactual exercises on data without trade deficits, which we obtain by first simulating the trade equilibrium with balanced trade. This preliminary simulation is always performed with our preferred value of $\kappa=2$.
} 
rise of China. ${ }^{25}$ The first step is to obtain predicted changes in US expenditure shares from running a specification similar to ADH's first-stage regression,

$$
\hat{\lambda}_{C h i n a, U S, s}=\alpha+\beta \hat{\lambda}_{C h i n a, \text { Other }, s}+\varepsilon_{s},
$$

where $\hat{\lambda}_{C h i n a, \text { Other }, s} \equiv \frac{\sum_{j \in \text { Other }}^{J} \lambda_{\text {China,j,s }}^{2011}}{\sum_{j \in \text { Other }}^{J} \lambda_{\text {China,j,s }}^{200}}$. In a second step we calibrate $\hat{T}_{C h i n a, s}$ so that the model-implied changes in the US expenditure share on imports from China, $\hat{\lambda}_{C h i n a, U S, s}$, match the predicted values from the first step.

\subsection{Aggregate and distributional welfare effects}

The results for the US welfare effects of the China shock as calibrated above are shown in Table 3 for four different values of $\kappa: 1,2,4$ and $\infty$, and for $\theta_{s}=5$ for all $s .{ }^{26}$ The first column shows the aggregate welfare effect for the case with no inequality aversion, $\hat{W}_{U S}$, while the next four columns show the mean, the coefficient of variation $(\mathrm{CV})$, and the minimum and maximum for the group-level welfare changes, $\hat{W}_{U S, g}$. The last column shows the welfare effect according to the multi-sector ACR formula.

Focusing first on the results for our preferred value of $\kappa=2$, the model implies US aggregate welfare gains from the rise of China of $0.25 \%$, with an average gain across groups of $0.32 \% .^{27}$ The CV is $56 \%$, and the range is $[-1.64 \%, 1.34 \%]$. While one group loses $1.64 \%$ of its real income, almost $97 \%$ of groups experience positive gains from the rise of China (see Appendix Figure A.1, panel b). There are 5 groups who lose more than $0.5 \%$ of their real income, whereas 110 groups have real income gains above $0.5 \%$. Low and high-educated groups experience almost identical average gains, but the CV for high-educated groups is much larger at $67 \%$, versus $40 \%$ for low-educated groups. ${ }^{28}$

\footnotetext{
${ }^{25}$ This calibration is inspired by the procedure in Caliendo et al. (2015), who calibrate $\hat{T}_{C h i n a, s}$ to match predicted changes in US imports from China. Instead of imports, we focus on the expenditure shares $\lambda_{C h i n a, U S, s}$, and thereby avoid any complications arising from matching sectoral deflators for US imports across simulations and data.

${ }^{26}$ For reasons of comparability, the results for different values of $\kappa$ correspond to the shock $\hat{T}_{C h i n a, s}$ as calibrated for $\kappa=2$. Separately calibrating $\hat{T}_{C h i n a, s}$ for each value of $\kappa$ leads to similar results - see Appendix Table A.3.

${ }^{27}$ To provide context for this number, Hsieh and Ossa (2016) find welfare gains for the US between 0 and $0.03 \%$. The difference with our results is likely due to the fact that we calibrate Chinese technology growth to fit predicted Chinese exports, whereas Hsieh and Ossa (2016) calculate technological growth based on firm-level data.

${ }^{28}$ This finding differs from the results in Lee (2016), who finds that the wage skill-premium increases in the United States as a consequence of the China shock. As discussed in Section 2.6, differences in the
} 
Table 3: The Welfare Effects of the China Shock on the US

\begin{tabular}{ccccccc}
\hline$\kappa$ & $\widehat{W}_{U S}$ & Mean & CV & Min. & Max. & $\prod_{s} \widehat{\lambda}_{s}^{-\beta_{s} / \theta_{s}}$ \\
\hline$\rightarrow 1$ & 0.29 & 0.38 & 0.87 & -2.24 & 2.56 & 0.20 \\
2 & 0.25 & 0.32 & 0.56 & -1.64 & 1.34 & 0.20 \\
4 & 0.23 & 0.28 & 0.36 & -1.01 & 0.76 & 0.21 \\
$\rightarrow \infty$ & 0.24 & 0.24 & 0.00 & 0.24 & 0.24 & 0.24 \\
\hline
\end{tabular}

The first column displays the aggregate welfare effect of the China shock for the US, in percentage terms $\left(100\left(\widehat{W}_{U S}-1\right)\right)$, and the second column shows the mean welfare effect: $100\left(\frac{1}{G} \sum_{g} \widehat{W}_{U S, g}-1\right)$. The third column shows the coefficient of variation (CV), and for the fourth and fifth column we have Min. $\equiv \min _{g} 100\left(\widehat{W}_{U S, g}-1\right)$ and Max. $\equiv \max _{g} 100\left(\widehat{W}_{U S, g}-1\right)$, respectively. The final column displays $100\left(\prod_{s} \hat{\lambda}_{U S, U S, s}^{-\beta_{U S, s} / \theta_{s}}-1\right)$. The values for $\hat{T}_{C h i n a, s}$ are calibrated for $\kappa=2$.

In Figure 1, we plot the geographical distribution of the welfare effects from the China shock, with the low-educated workers and high-educated groups in panels (a) and (b) respectively. The correlation of the group-level welfare effects between lowand high-educated groups (across commuting zones) is $78 \%$, and this high correlation is reflected in the strong similarity in the geographic distribution of the welfare effects in the two panels of Figure 1. Still, for low-educated workers, the region around South-Central and Southern Appalachia represents a particularly stark concentration of groups with gains in the bottom sixth of the gains distribution. Regions where both low- and high-educated groups tend to experience low gains (or losses) are Northern Appalachia, the Midwest, the Northeast, and the southern parts of California and Arizona. $^{29}$

The distributional impact of the China shock depends on $\kappa$, as a lower $\kappa$ leads to higher dispersion in the gains from trade due to a stronger pattern of worker-level comparative advantage. The simulation results confirm this theoretical prediction, as both the CV and the difference between maximal and minimal $\hat{W}_{U S, g}$ tend to zero as $\kappa$ ap-

welfare effect of a shock in our model are determined by the term $\left(\sum_{s} \pi_{g s} \hat{r}_{s}\right)^{1 / \kappa}$, and this turns out to be very similar across low and high education groups.

${ }^{29}$ Our quantitative analysis assumes that the effect of the China shock on prices are the same across groups. This is consistent with (Bai and Stumpner 2017), who find "no evidence for heterogeneous effects across consumer groups by income or region." 
Figure 1: Geographical distribution of the welfare gains from the rise of China

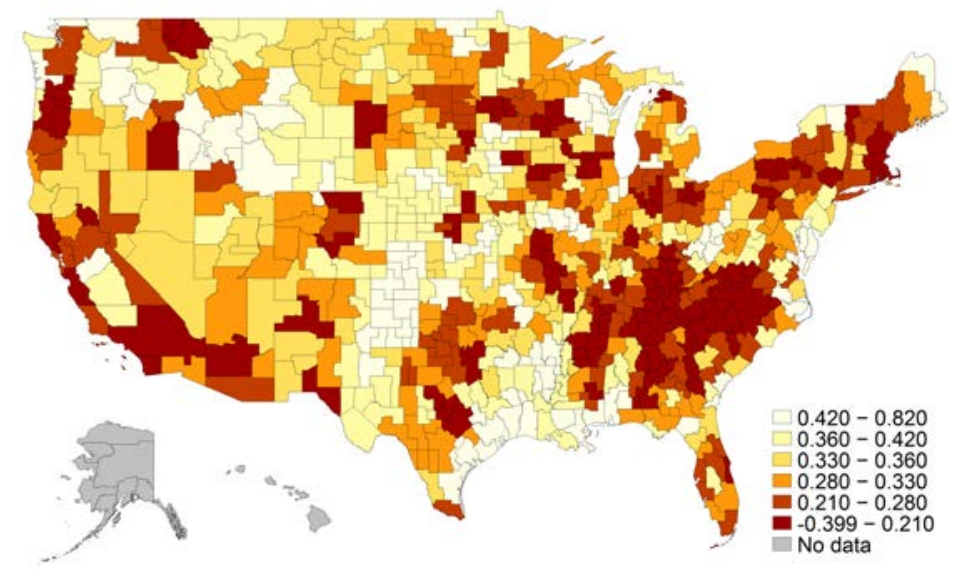

(a) Low-educated workers

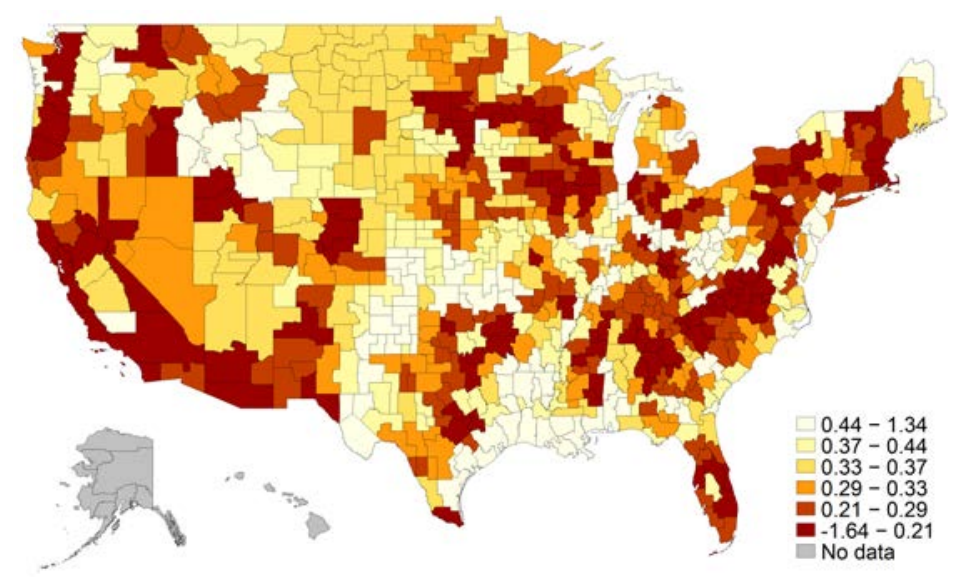

(b) High-educated workers

This figure plots the geographic distribution of $100\left(\hat{W}_{g}-1\right)$, where $\hat{W}_{g}$ are the welfare effects for group g in the US from the counterfactual rise of China, for our preferred value of $\kappa=2$. Panel (a) and (b) display results for the low-educated and high-educated groups respectively.

proaches infinity (see Table 3). ${ }^{30}$ For $\kappa \rightarrow 1$, the CV reaches a maximum at 87\%, and the range is $[-2.24 \%, 2.56 \%]$. Note that for $\kappa=1,2,4$ in Table 3 there are groups who lose from the rise of China. ${ }^{31} 32$

\footnotetext{
${ }^{30}$ In additional simulation results, available on request, we find that the CV falls monotonically with $\kappa$.

${ }^{31}$ Appendix Figure A.1 visualizes how $\kappa$ governs the distributional impact of the China shock by plotting the full distribution of $\hat{W}_{U S, g}$ for our different values of $\kappa$.

${ }^{32}$ In the final column, we notice that $\kappa$ indirectly also affects the multi-sector ACR term, even though $\hat{T}_{C h i n a, s}$ is held constant. This is because $\kappa$ affects wage changes in all countries and thereby also the changes in expenditure shares $\hat{\lambda}_{i j s}$.
} 


\subsection{Import competition and income}

In Section 2.6, we showed that $\ln \left(\hat{Y}_{g} / \hat{Y}\right) \approx \frac{1}{\kappa} \ln \sum_{s} \pi_{g s} \hat{r}_{s}=-\frac{1}{\kappa} \ln \hat{I}_{g}$. We check on the accuracy of this approximation for the calibrated China shock by using the model to compute the implied group-level income changes for different values of $\kappa$ and then running the following regression on the resulting simulated data:

$$
\ln \hat{y}_{g}=\alpha+\beta \ln \sum_{s} \pi_{g s} \hat{r}_{s}+\varepsilon_{g}
$$

Figure 2 plots the resulting values of $\hat{\beta}$ for each $\kappa$. As expected, $\hat{\beta}$ decreases monotonically with $\kappa$, with a relationship very well approximated by $\hat{\beta}=1 / \kappa .{ }^{33}$

Figure 2: A Bartik test

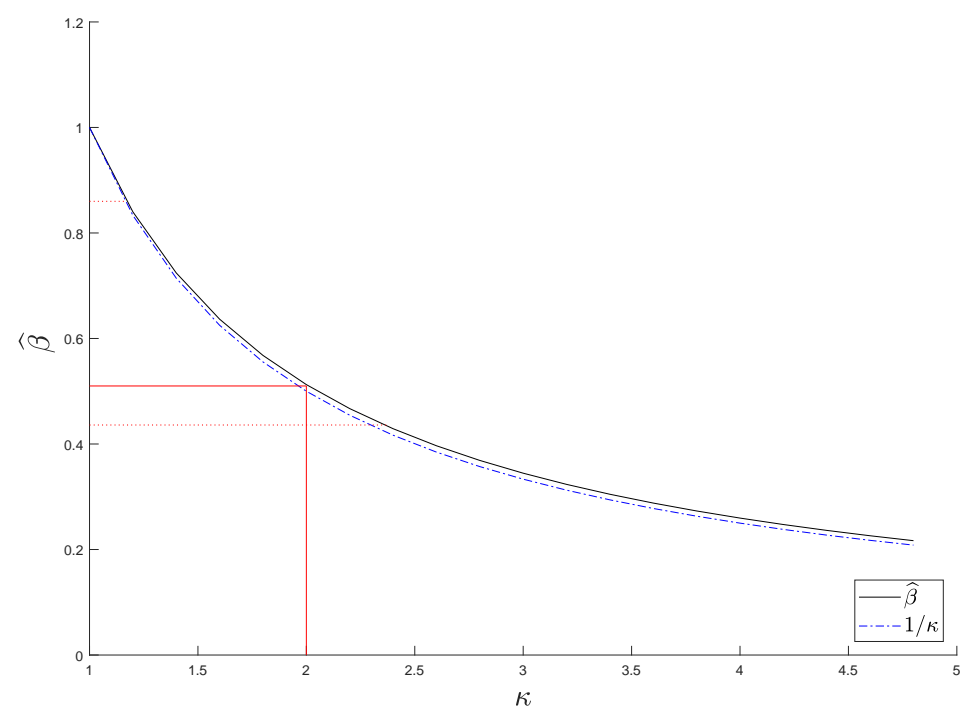

The coefficient $\hat{\beta}$, on the vertical axis, is estimated in the following regression: $\ln \hat{y}_{g}=\alpha+\beta \ln \sum_{s} \pi_{g s} \hat{r}_{s}+\varepsilon_{g}$, which is run separately for different sets of simulation outcomes for $\hat{y}_{g}$ and $\hat{r}_{s}$. Each set of simulation outcomes is obtained for a different value of $\kappa$ (horizontal axis). The vertical line represents the preferred value for $\kappa$ from the structural estimation in Section 4.3, and the solid horizontal line represents the associated value for $\beta$. The dotted horizontal lines represent the values of one standard error above or below the point estimate for $\hat{\beta}$ in regression (21) for the earnings column in Table 4.

\footnotetext{
${ }^{33}$ Figure A.2 in the Appendix also shows that the model-implied values for $\ln \left(\hat{Y}_{g} / \hat{Y}\right)$ and $\ln \sum_{s} \pi_{g s} \hat{r}_{s}$ across groups in the United States for the impact of the calibrated China shock are basically linear even for $\kappa>1$.
} 
The finding that $\ln \hat{y}_{g} \approx \ln \hat{y}+\frac{1}{\kappa} \ln \sum_{s} \pi_{g s} \hat{r}_{s}$ is important for two reasons. First, it confirms that $\frac{1}{\kappa} \ln \sum_{s} \pi_{g s} \hat{r}_{s}$ (or $-\frac{1}{\kappa} \ln \hat{I}_{g}$ ) can serve as an approximate sufficient statistic for a group's welfare change relative to that for the economy as a whole. This is useful because, in contrast to the exact result in Proposition 1, it does not require knowing the group-level employment changes $\hat{\pi}_{g s} \cdot{ }^{34}$ Second, the formula suggests an empirical validation test of our model and structural estimation of $\kappa$ in Table 2. Specifically, since we know that $\beta \approx \frac{1}{\kappa}$, we can estimate Equation 21 on observed data and compare the implied values for $\kappa$ with those from the structural estimation in Section 4.3.

We estimate $\beta$ on the observed data using the variation induced by the China shock by instrumenting for $\ln \sum_{s} \pi_{g s} \hat{r}_{s}$ in (21) with $\sum_{s} \pi_{g s}^{M} \Delta I P_{s t}^{C h i n a} \rightarrow$ Other . The exclusion restriction in this IV regression is that sector-level growth in China affects group-level incomes only through its effect on US sectoral output and a group's initial pattern of specialization. As shown in Table 4, the first stage has the expected sign and has sufficient statistical power. The estimated coefficient $\hat{\beta}$ is positive and strongly statistically significant in all specifications, which corroborates the theoretical prediction that regional income changes depend positively on trade-induced changes in $\sum_{s} \pi_{g s} \hat{r}_{s}$. The magnitudes of the $\hat{\beta}$ estimates are also consistent with the theoretical analysis from Section 2.6 and with our simulation results, both of which implied $\hat{\beta}<1$. More importantly, the results validate our structural estimation approach for $\kappa$, since the $\hat{\beta}$ estimates are consistent with the results of Table 2. For our estimate $\kappa=2$, the model-implied $\hat{\beta}$ is equal to 0.5 , which is below the point estimates in Table 4 , but within their respective 95\% confidence intervals (see Figure 2).

\subsection{Inequality-adjusted welfare effect}

We summarize the aggregate and distributional welfare effects of the rise of China for the US by computing the inequality-adjusted welfare effect from Equation (17). As shown in Figure 3, for finite values of $\kappa, \hat{U}_{U S}$ is weakly decreasing in the coefficient of inequality aversion $\rho .{ }^{35}$ For our estimated value of $\kappa=2, \hat{U}_{U S}$ remains initially almost

\footnotetext{
${ }^{34}$ As in Kovak (2013), the relationship we find between $\ln \hat{y}_{g}$ and $\ln \sum_{s} \pi_{g s} \hat{r}_{s}$ also provides a theoretical foundation for the empirical use of Bartik-style regressors which assign national sectoral changes to groups based on their initial sectoral composition. Relative to Kovak (2013), our model allows for heterogeneous labor and imperfect mobility across sectors.

${ }^{35}$ The theory does not predict how $\hat{U}_{U S}$ changes as function of $\rho$. Based on the result in equation 18, one could think that the Generalized Mean Inequality (GMI) has implications for how $\hat{U}_{U S}$ changes with the
} 
Table 4: The rise of China and the Bartik measure for import competition

(a) First Stage: $\ln \sum_{s} \pi_{g s} \hat{r}_{s}=\alpha+\beta \sum_{s \in M} \pi_{g s}^{M} \Delta I P_{s t}^{C h i n a} \rightarrow$ Other $+\varepsilon_{g}$

\begin{tabular}{lccc}
\hline \hline & $(1)$ & $(2)$ & $(3)$ \\
Definition of $\pi_{g s}$ & Workers & Hours & Earnings \\
\hline \hline$\sum_{s \in M} \pi_{g s}^{M} \Delta I P_{s t}^{C h i n a \rightarrow \text { Other }}$ & -0.00348 & -0.00779 & -0.00151 \\
& $(0.000982)$ & $(0.00218)$ & $(0.000505)$ \\
\hline F Statistic & 12.52 & 12.71 & 8.924 \\
\hline \hline
\end{tabular}

(b) Second Stage: $\ln \hat{y}_{g}=\alpha+\beta \ln \sum_{s} \pi_{g s} \hat{r}_{s}+\varepsilon_{g}$

\begin{tabular}{lccc}
\hline \hline & $(1)$ & $(2)$ & $(3)$ \\
\hline $\ln \sum_{s} \pi_{g s} \hat{r}_{s}$ & 0.712 & 0.703 & 0.648 \\
& $(0.228)$ & $(0.221)$ & $(0.212)$ \\
\hline Observations & 1444 & 1444 & 1444 \\
\hline \hline
\end{tabular}

IV-estimation results for specification (21), where $y_{g}$ is measured as average earnings per worker. Labor shares $\pi_{g s}$ are measured as the share of workers, share of labor hours and share of earnings for columns 1 , 2 and 3 respectively. Standard errors (in parentheses) are calculated as in Conley (1999) and with a cutoff for the spatial correlation at approximately $400 \mathrm{~km}$.

equal to the standard welfare effect, then starts decreasing around $\rho=4$, and finally becomes negative for $\rho>13$. Which are reasonable values for $\rho$ ?

To answer this question, we looked into several different interpretations for the social welfare function (SWF) in (17). The first interpretation is that the SWF in (17) comes from a political process that aggregates the views and interests across agents in the economy. According to this view, $\rho$ could be calibrated based on actual policies, for example the progressivity of the tax system. As discussed Antras et al. (2016), this implies $\rho<1$ in the US. ${ }^{36}$ The second interpretation is that the SWF in Equation (17) reflects a utilitarian approach to social welfare, with the utility of an individual with (real) income $x$ being $u(x)=x^{1-\rho}$. In this case $\rho$ can be calibrated based on the curvature of power $1-\rho$, but the GMI does not apply to $\hat{U}_{U S}$ because the weights $\omega_{g}$ are themselves dependent on the power $1-\rho$.

${ }^{36}$ Carrère et al. (2015) use the same approach and cite studies for the US and the United Kingdom to set $\rho=1$. 
Figure 3: Inequality-Adjusted welfare-effects from the China shock

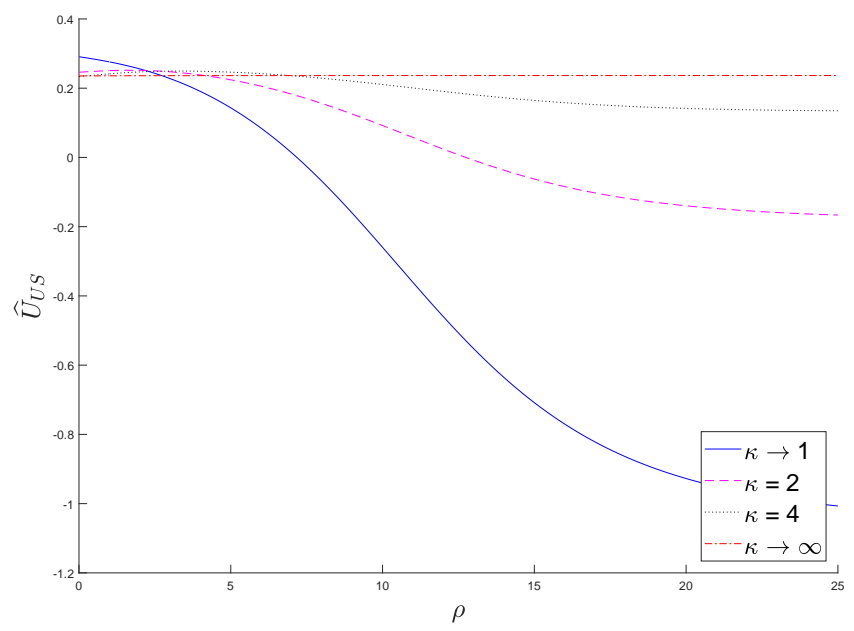

The figure plots the relationship between $\hat{U}_{U S}$, the inequality-adjusted welfare effects of the rise of China, with $U_{U S} \equiv \eta\left(\sum_{g} l_{g} W_{g}^{1-\rho}\right)^{1 /(1-\rho)}$. Here, $\rho$ which is the coefficient of relative risk aversion for the agent behind the veil of ignorance and $\eta \equiv \frac{\Gamma\left(1-\frac{1-\rho}{\kappa}\right)^{\frac{1}{1-\rho}}}{\Gamma\left(1-\frac{1}{\kappa}\right)}$. The vertical axis displays $100\left(\hat{U}_{U S}-1\right)$.

utility with respect to income, as for example in Layard, Mayraz and Nickell (2008), who find that $\rho \in[1,2]$. One can also use agents' intertemporal elasticity of substitution to estimate the curvature parameter - in the macro literature the common view is that $\rho \approx 1$ (see e.g. Lucas 2003), although a review of the literature leads Hall (2009) to the conclusion that $\rho=2$. The third approach is to think of Equation (17) as representing the ex-ante utility of a risk-averse agent "behind the veil of ignorance" regarding its productivity vector $\left(Z_{1}, \ldots, Z_{S}\right)$ - see for instance Jones and Klenow (2016). In this case $\rho$ would need to be calibrated based on people's aversion to risk. Using an indirect approach based on the labor supply elasticity, Chetty (2006) finds that $\rho<2$, while more direct estimates based on people's decisions under uncertainty range from $\rho=1$ in Bombardini and Trebbi (2012) and $\rho \approx 3$ in Paravisini, Rappoport and Ravina (2016). ${ }^{37}$

Our conclusion from this literature review is that plausible values for $\rho$ tend to be lower than $4 .^{38}$ For these values and for $\kappa=2$, the inequality-adjusted welfare effect

\footnotetext{
${ }^{37}$ There is also a literature estimating risk aversion to rationalize the equity premium. This leads to high estimated values for $\rho \in[10,100]$, but see Lucas (2003) and Hall (2009) for skeptical takes on that approach.

${ }^{38}$ In contrast to this positive perspective, one can also argue that inequality aversion is a normative concept and that the choice of $\rho$ cannot be settled by empirical evidence (see e.g. Rawls 2001). Our discussion
} 
of the China shock for the US is almost identical to the standard welfare effect with no inequality aversion ( $\rho=0$ ). Even for $\kappa \rightarrow 1$, the inequality-adjusted welfare effect remains positive for all plausible degrees of inequality aversion. ${ }^{39}$ We therefore conclude that the positive impact of the China shock on inequality-adjusted welfare in the US is a robust finding, while the precise comparison of the standard and the inequalityadjusted welfare effect is sensitive to the values of $\rho$ and $\kappa$.

Coming back to the finding that the inequality-adjusted welfare effect of the China shock is weakly decreasing in $\rho$, we can infer from Figure 4 that this is due to the existence of a set of initially poor groups that experience a higher than average increase in import competition, $\hat{I}_{g}>1$. In turn, this comes from the fact that the China shock $\sum_{s \in M} \pi_{g s} \Delta I P_{s t}^{C h i n a \rightarrow O t h e r}$ is stronger for groups with lower initial income - see Figure A.4 in the Appendix. However, an important caveat applies to this finding, as it is sensitive to our measurement of group-level income. Remember that we needed to adjust the sectoral earnings as observed in the American Community Survey to make it compatible with WIOD (see Section 3). When we don't perform this adjustment, then the China shock appears neutral or slightly pro-poor (see Figure A.5 in the Appendix). This implies that the finding that the China shock is pro-rich is fragile, as it depends on how non-labor income is apportioned across groups.

here is therefore conditional on accepting the positive approach for calibrating inequality aversion in the literature, and we acknowledge that different conclusions result from higher values of $\rho$.

${ }^{39}$ Of course, even with $\rho>13$, if society has access to lump-sum transfers then it feasible to ensure that the inequality-adjusted welfare effect of the China shock is positive. 
Figure 4: Initial group-level income and our Bartik measure of import competition

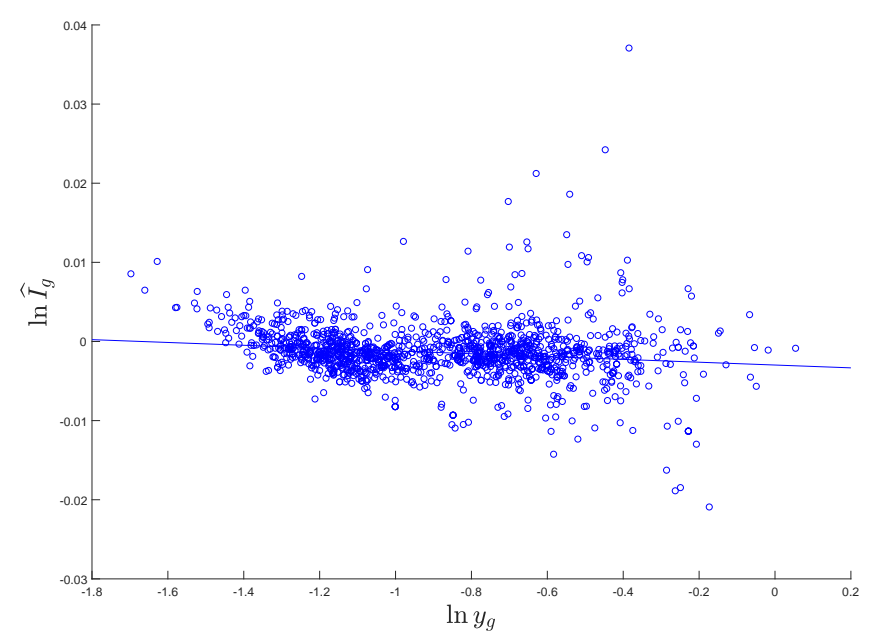

The figure plots the relationship between $\ln \hat{I}_{g}=\ln \left(\sum_{s} \pi_{i g s} \hat{r}_{i s}\right)^{-1}$, our measure for the change in regional import-competition ( computed for $\kappa=2$ ), and the logarithm of group-level average income per worker. The solid line displays the linear fit for this relationship.

\section{Gains from Trade}

In this section we compute the aggregate and group-level gains from trade as described in Section 2, i.e., by computing the negative of the proportional gains from a counterfactual move back to autarky. Table 5 summarizes the results. For our estimated value of $\kappa=2$, the aggregate gains from trade with no inequality aversion are $1.52 \%$. As suggested by the theory, the gains from trade decrease with $\kappa$, but the effect is small, going from $1.60 \%$ for $\kappa=1$ to $1.45 \%$ for $\kappa \rightarrow \infty$.

As in the analysis of the China shock, the main effect of $\kappa$ is on the distribution of the gains from trade across groups, with the CV decreasing from $59 \%$ for $\kappa \rightarrow 1$ to $0 \%$ for $\kappa \rightarrow \infty$. For our preferred value of $\kappa=2$, the CV is 33\%, and the range is [-3.19, 2.41]. In total, only 26 groups lose from trade, but the distribution of gains is skewed to the left, with a thick tail of low gains (see Appendix Figure A.3).

As implied by the analysis above (Sections 2.6 and 5.3), our Bartik measure of import competition $I_{g} \equiv \sum \pi_{g s} \frac{\beta_{s}}{r_{s}}$ perfectly ranks groups in terms of winners and losers from trade for all values of $\kappa$ (see Appendix Figure A.6). The textile industry faces the highest degree of import competition (with $\frac{\beta_{s}}{r_{s}}=1.51$; Appendix Table A.1), so groups par- 
Table 5: Aggregate and Group-level Gains from Trade

\begin{tabular}{ccccccc}
\hline$\kappa$ & $\widehat{W}_{U S}$ & Mean & CV & Min. & Max. & $\prod_{s} \widehat{\lambda}_{s}^{-\beta_{s} / \theta_{s}}$ \\
\hline$\rightarrow 1$ & 1.60 & 1.80 & 0.59 & -7.86 & 3.36 & 1.45 \\
2 & 1.52 & 1.63 & 0.33 & -3.19 & 2.41 & 1.45 \\
4 & 1.48 & 1.54 & 0.18 & -0.87 & 1.93 & 1.45 \\
$\rightarrow \infty$ & 1.45 & 1.45 & 0.00 & 1.45 & 1.45 & 1.45 \\
\hline
\end{tabular}

The first column displays the aggregate gains from trade for the US, in percentage terms $\left(100\left(1-\widehat{W}_{U S}\right)\right)$ and the second column shows the mean welfare effect: $100\left(\frac{1}{G} \sum_{g} 1-\widehat{W}_{U S, g}\right)$. Here, $\widehat{W}_{U S}$ and $\widehat{W}_{U S, g}$ are the aggregate and group-level welfare change from a return to autarky for the US. The third column shows the coefficient of variation (CV), and for the fourth and fifth column we have Min. $=\min _{g} 100\left(1-\widehat{W}_{U S, g}\right)$ and Max. $=\max _{g} 100\left(1-\widehat{W}_{U S, g}\right)$, respectively. The final column displays $100\left(1-\prod_{s} \widehat{\lambda}_{U S, U S, s}^{-\beta_{U S, s} / \theta_{s}}\right)$.

ticularly specialized in this industry will gain the least. Interestingly, there is a large region with heavy concentration of groups facing particularly strong import-competition - largely due to due to specialization in the textile industry - centered around the SouthCentral and Southern Appalachia regions (see Appendix Figure A.7).

Figure 5 shows that for $\rho>0$, the inequality-adjusted gains from trade are lower than the standard gains, $I G T<G T$, and that $I G T$ decreases with the $\rho$. This is a reflection of the fact that, as illustrated in Figure 6, the index of import competition is higher for poorer groups. And contrary to the case with the China shock, this is true even if we compute the index of import competition and average earnings using the American Community Survey rather than the adjusted data used for the model simulations (see Appendix Figure A.8). Note however that the IGT remain positive, except for values of $\rho$ (i.e. $\rho>11$ for $\kappa=2$ ) that seem implausibly high in light of the discussion in the previous section. For $\rho=2$, the IGT are $1.37 \%$. 
Figure 5: Inequality-adjusted Gains from Trade

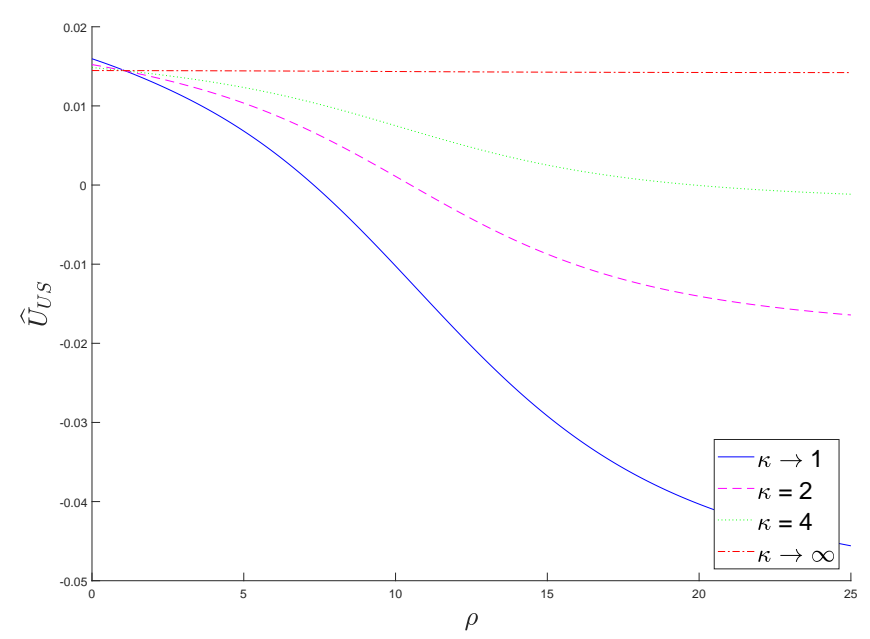

The figure plots the relationship between the inequality-adjusted gains from trade $\hat{U}_{U S}$, with $U_{U S} \equiv$ $\eta\left(\sum_{g} l_{g} W_{g}^{1-\rho}\right)^{1 /(1-\rho)}$, and $\rho$. Here, $\rho$ which is the coefficient of relative risk aversion for the agent behind the veil of ignorance, and $\eta \equiv \frac{\Gamma\left(1-\frac{1-\rho}{\kappa}\right)^{\frac{1}{1-\rho}}}{\Gamma\left(1-\frac{1}{\kappa}\right)}$. The vertical axis displays $100\left(1-\hat{U}_{U S}\right)$.

Figure 6: Group-level Import Competition and Income

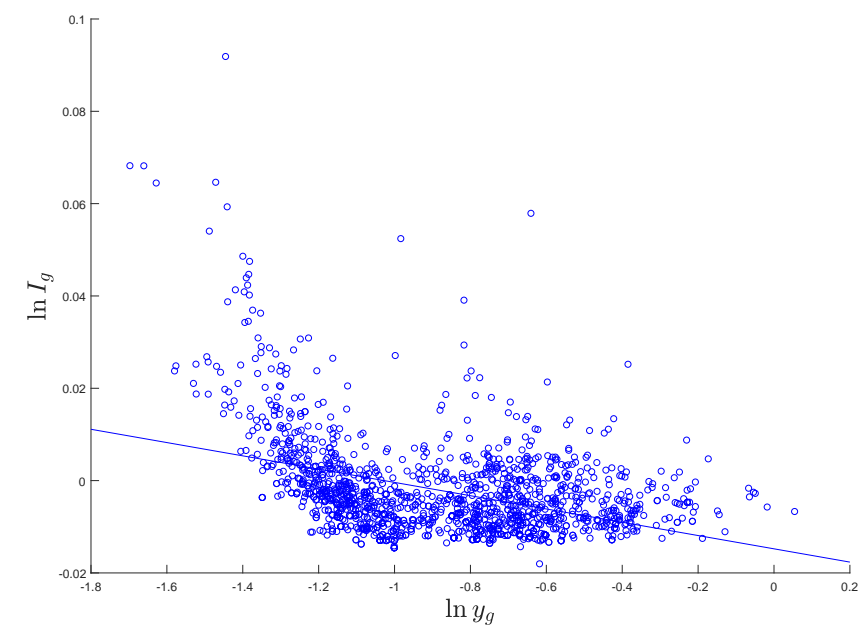

The figure plots the relationship between $\ln I_{g} \equiv \ln \sum_{s} \pi_{i g s} \frac{\beta_{i s}}{r_{i s}}$, our measure for regional importcompetition, and the logarithm of group-level average income per worker. 


\section{$7 \quad$ Extensions and Discussion}

In this section we discuss extensions to allow for an input-output structure and trade costs affecting trade between groups inside a country, and we discuss the link between our model and the empirical literature on the employment effects of the China shock.

\subsection{Intermediate Goods}

Extending the model to allow for an input-output structure is potentially important because a significant share of the value of production in a sector originates from other sectors, and taking this into account may affect the effects of trade on wages $\hat{w}_{i s}$ and hence the welfare effects across groups.

The labor supply of the model is exactly as in the baseline model (see Equations 3 and 4). On the trade side, the model is identical to Caliendo and Parro (2015), except that wages are now sector-specific (i.e. wages are $w_{i s}$ instead of $w_{i}$ ). Hence, trade shares and the price indices are as in equations (1) and (2), but instead of $w_{i s}$ we now have $c_{i s}$, where $c_{i s}$ is given by

$$
c_{i s}=w_{i s}^{1-\alpha_{i s}} \prod_{k} P_{i k}^{\alpha_{i k s}}
$$

with

$$
P_{j s}=\gamma_{s}^{-1}\left(\sum_{i} T_{i s}\left(\tau_{i j s} c_{i s}\right)^{-\theta_{s}}\right)^{-1 / \theta_{s}} .
$$

Here, the $\alpha_{i k s}$ are the Cobb-Douglas input shares: a share $\alpha_{i k s}$ of the output of industry $s$ in country $i$ is used buying inputs from industry $k$, and $1-\alpha_{i s}$ is the share spent on labor, with $\alpha_{i s}=\sum_{k} \alpha_{i k s}$. Given this structure, we derive in Appendix D the following expression for a group's welfare change:

Proposition 3. Given some trade shock, the ex-ante percentage change in the real income of group $g$ in country $i$ is given by

$$
\hat{W}_{i g}=\prod_{s, k} \hat{\lambda}_{i i k}^{-\beta_{i s} \widetilde{a}_{i s k} / \theta_{s}} \cdot \prod_{s, k} \hat{\pi}_{i g k}^{-\beta_{i s} \widetilde{a}_{i s k}\left(1-\alpha_{i k}\right) / \kappa_{i g}}
$$

where $\widetilde{a}_{i s k}$ is the typical element of matrix $\left(I-\Upsilon_{i}^{T}\right)^{-1}$ with $\Upsilon_{i} \equiv\left\{\alpha_{i k s}\right\}_{k, s=1, \ldots, S}$.

For this extended model, for $\kappa=2$ we find a gain from the China shock of $0.34 \%$ and 
gains from trade of $2.98 \%$ (see Table 6) ${ }^{40}$ These gains are higher than in the baseline model, which is in line with the findings in Costinot and Rodríguez-Clare (2014), who explain that the input-output loop in this model leads to an additional round of welfare gains from a given trade shock.

The distributional effects of both the China shock and opening to trade are somewhat mitigated compared to the baseline model. The CV is lower in both cases, and the range of group-level welfare effects is slightly more compressed. Still, the correlation between the group-level welfare effects in the two versions of the model is $92 \%$ and 97\%, for the China shock and the gains from trade respectively (see Appendix Figure A.9). Hence, the ranking of groups in terms of relative welfare effects is a robust finding of the baseline model.

\subsection{Within-US trade costs}

An admittedly strong assumption of the analysis so far has been that there are no trade costs within a country, which implied that $P_{i s}$ and $w_{i s}$ are equalized across groups within a country. In this section we relax this assumption for the US by allowing for trade costs between US states (in addition to trade costs across countries), while retaining the assumption of frictionless trade within states.

Conceptually, we return to the baseline model from Section 2, the only difference being that US states now play a role identical to the role of countries in the baseline model. In particular, if group ig belongs to state $n$ then

$$
\hat{W}_{i g}=\prod_{s} \hat{\lambda}_{n n s}^{-\beta_{n s} / \theta_{s}} \cdot \prod_{s} \hat{\pi}_{i g s}^{-\beta_{n s} / \kappa_{i g}}
$$

We use this framework to analyze how the quantitative results change when we allow for within-US trade costs. We construct the necessary trade data to allow for trade costs between US states by using the Commodity Flow Survey (see Appendix B for details). ${ }^{41}$

The summary statistics for the updated model differ only modestly from those for

\footnotetext{
${ }^{40}$ Since the labor supply side of the model is unaltered compared to the baseline model, the $\kappa$ estimation from Section 4.3 remains valid. This explains why we continue to use the same values for $\kappa$ in the quantification of this model.

${ }^{41}$ In principle, the model could allow for trade costs between geographical units at an even more disaggregated level, but we are not aware of reliable trade data at lower levels of disaggregation that cover the entire United States.
} 
Table 6: Counterfactual analysis for the model with intermediates

(a) The rise of China

\begin{tabular}{ccccccc}
\hline$\kappa$ & $\widehat{W}_{U S}$ & Mean & CV & Min. & Max. & $\prod_{s} \widehat{\lambda}_{s}^{-\beta_{s} / \theta_{s}}$ \\
\hline$\rightarrow 1$ & 0.39 & 0.44 & 0.58 & -1.68 & 2.21 & 0.31 \\
2 & 0.34 & 0.38 & 0.35 & -1.08 & 1.25 & 0.31 \\
4 & 0.33 & 0.35 & 0.21 & -0.54 & 0.78 & 0.31 \\
$\rightarrow \infty$ & 0.31 & 0.31 & 0.00 & 0.31 & 0.31 & 0.31 \\
\hline
\end{tabular}

(b) Gains from trade

\begin{tabular}{ccccccc}
\hline$\kappa$ & $\widehat{W}_{U S}$ & Mean & CV & Min. & Max. & $\prod_{s} \widehat{\lambda}_{s}^{-\beta_{s} / \theta_{s}}$ \\
\hline 1 & 3.08 & 3.30 & 0.34 & -5.66 & 4.66 & 2.88 \\
2 & 2.98 & 3.09 & 0.18 & -1.36 & 3.79 & 2.88 \\
4 & 2.93 & 2.99 & 0.10 & 0.77 & 3.34 & 2.88 \\
$\rightarrow \infty$ & 2.88 & 2.88 & 0.00 & 2.88 & 2.88 & 2.88 \\
\hline
\end{tabular}

The tables show summary statistics for welfare effects of US groups for the model with an input-output structure. Panel (a) shows results for the counterfactual rise of China, where the values for $\hat{T}_{C h i n a, s}$ are calibrated for $\kappa=2$. Panel (b) shows results for group-level gains from trade. The first column displays the aggregate gains from trade for the US, in percentage terms $\left(100\left(1-\widehat{W}_{U S}\right)\right)$ and the second column shows the mean welfare effect: $100\left(\frac{1}{G} \sum_{g} 1-\widehat{W}_{U S, g}\right)$. Here, $\widehat{W}_{U S}$ and $\widehat{W}_{U S, g}$ are the aggregate and group-level welfare change from a return to autarky for the US. The third column shows the coefficient of variation (CV), and for the fourth and fifth column we have Min. $=\min _{g} 100\left(1-\widehat{W}_{U S, g}\right)$ and Max. $=\max _{g} 100(1-$ $\left.\widehat{W}_{U S, g}\right)$, respectively. The final column displays $100\left(1-\prod_{s} \widehat{\lambda}_{U S, U S, s}^{-\beta_{U S, s} / \theta_{s}}\right)$.

the baseline model. The average welfare gains in the updated model are somewhat smaller than in the baseline model, for both the rise of China and the gains from trade (see Table 7). ${ }^{42}$ For instance, for $\kappa=2$, we found a mean welfare change of $0.32 \%$ due to the rise of China in the baseline model, while in the current model we find a mean welfare change of $0.23 \%$. On the distributional side, the results are broadly similar for the China shock, ${ }^{43}$ but the distribution of the gains from trade is more dispersed in the

\footnotetext{
${ }^{42}$ The gains from trade are computed as the negative of the percentage change in welfare from a counterfactual move to autarky by the whole United States but allowing US states to trade among themselves.

${ }^{43}$ For instance, the range of welfare effects for $\kappa=2$ is $[-1.6,1.47]$ in the current model, compared to
} 
model with states as countries. For $\kappa=2$, the CV is now 0.44 and the range of grouplevel gains from trade is $[-4.24,2.90]$, compared to a CV of 0.33 and a range of [-3.19, 2.41] in the baseline model.

While the similarity in the summary statistics across the two models is reassuring, we are mostly interested in how the precise incidence of the counterfactual shocks across groups changes when we model US states as separate countries. We find that the group-level welfare changes correlate strongly across the two models, but not perfectly: the correlation is $65 \%$ for the China shock and $47 \%$ for the return to autarky (see Appendix Figure A.10). Importantly, the correlation in the Roy term across the two models is even stronger, at $77 \%$ for the China shock and $72 \%$ for the return to autarky. The Roy term also accounts for most of the variance in the welfare effects, since for the China shock $78 \%$ of the variance in $\ln \hat{W}_{i g}$ for US groups arises only from the variance in $\ln \prod_{s} \hat{\pi}_{i g s}^{-\beta_{n s} / \kappa}$. For the return to autarky this number is $70 \%$.

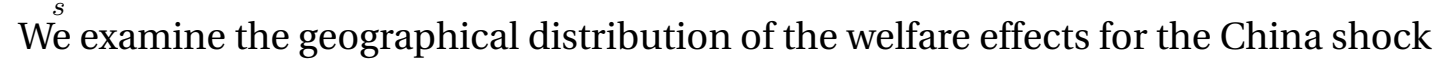
in Appendix Figure A.11. In line with the previous finding, the geographical pattern for $\hat{W}_{i g}$ (panels a and c) appears different from the corresponding pattern for the baseline model, but the patterns for the Roy terms (panels $b$ and d) appear similar. We find analogous results for the return to autarky (see Appendix Figure A.12). The difference in the geographic distribution of the group-level welfare effects between the two models is therefore mostly due to variation in the multi-sector ACR term across US states. This variation in the ACR term mainly arises from differences in expenditure shares $\beta_{n s}$ across states.

Importantly, we primarily implemented this extension of the model to examine the robustness of our results when allowing for variation in sectoral wages across US states. Given that the group-level Roy terms are broadly similar across the baseline and the current model, we conclude that the impact of the China shock on group-level labor reallocation is indeed relatively robust to such variation.

$[-1.64,1.34]$ in the baseline model. While the CV tends to be higher in the current model, this is mainly due to the lower mean welfare effect. Note also that since the US is now split into multiple countries, the CV of the welfare effects across all US groups no longer tends to 0 as $\kappa \rightarrow \infty$. 
Table 7: Counterfactual analysis when within-US trade is costly

(a) The rise of China

\begin{tabular}{ccccc}
\hline \multicolumn{1}{c}{$\kappa$} & Mean & CV & Min. & Max. \\
\hline$\rightarrow 1$ & 0.27 & 1.31 & -2.12 & 2.77 \\
2 & 0.23 & 0.90 & -1.60 & 1.47 \\
4 & 0.22 & 0.65 & -0.98 & 0.86 \\
$\rightarrow \infty$ & 0.20 & 0.39 & -0.23 & 0.45 \\
\hline
\end{tabular}

(b) Gains from trade

\begin{tabular}{ccccc}
\hline \multicolumn{1}{c}{$\kappa$} & Mean & CV & Min. & Max. \\
\hline$\rightarrow 1$ & 1.41 & 0.71 & -10.16 & 3.64 \\
2 & 1.35 & 0.44 & -4.24 & 2.90 \\
4 & 1.32 & 0.32 & -1.33 & 2.56 \\
$\rightarrow \infty$ & 1.29 & 0.27 & 0.55 & 2.24 \\
\hline
\end{tabular}

The tables show summary statistics for welfare effects of US groups for the model where US states are treated as individual countries. Panel (a) shows results for the counterfactual rise of China, where the values for $\hat{T}_{C h i n a, s}$ are calibrated for $\kappa=2$. Panel (b) shows results for group-level gains from trade. The first column shows the mean welfare effect: $100\left(\frac{1}{G} \sum_{g} \widehat{W}_{n g}-1\right)$ for all groups in the US. The second column shows the coefficient of variation (CV), and for the third and fourth column we have Min. $\equiv \min _{g} 100\left(\widehat{W}_{U S, g}-1\right)$ and Max. $\equiv \max _{g} 100\left(\widehat{W}_{U S, g}-1\right)$, respectively. We are unable to calculate welfare changes across all states and groups in the US without knowledge of the initial value of $P_{n}$ for each state.

\subsection{Employment Effects}

We have built a model with perfectly inelastic labor supply - as is standard in the literature on gains from trade - and with no mobility across groups (or regions). One obvious implication is that our model cannot generate changes in employment in response to trade shocks. Since such employment changes are one of the key empirical results in $\mathrm{ADH}$, we now discuss whether allowing for mobility, commuting or a positive labor supply elasticity could make our model consistent with those results.

At a theoretical level, the assumption that there is no mobility across regions can 
trivially be relaxed with no change in our results. Since groups differ only in the parameters of the distribution from which individuals draw their productivities (the $A_{\text {igs }}$ parameters), the fact that sector-level wages $w_{i s}$ are national implies that there is no incentive for an individual with some given productivity vector to switch to another region. But an alternative interpretation is that $A_{i g s}$ is the labor productivity of group $i g$ in sector $s$, and that individuals in all groups draw their productivity vector from the same distribution. According to this interpretation, individuals would have incentives to move across regions. In a previous version of this paper we showed how one can use data on mobility across regions to extend our counterfactual analysis to this alternative model. Unfortunately, the data requirements are severe, and we have left this analysis for future work. We note, however, that $\mathrm{ADH}$ find insignificant effects of the China shock on population shifts at the commuting zone level, and hence we expect that adding mobility in a way that is consistent with their evidence should not have sizable effects on our results. ${ }^{44}$

Employment could also adjust through changes in commuting patterns, as in Monte, Redding and Rossi-Hansberg (2015). Extending our model to allow for commuting and exploring the impact of the China shock in that setting is an interesting task but beyond the scope of this paper. Here we simply note that, as shown in Section 5, the regions that are most negatively affected by the China shock tend to be geographically concentrated, and so commuting is unlikely to be a significant margin of adjustment.

A final possible adjustment in employment to the trade shock arises from changes in the employment to population ratio, and this margin of adjustment is in fact central to the empirical analysis in $\mathrm{ADH}$. It is challenging to explain this employment adjustment by allowing for a choice between labor and leisure. This is because standard values of the elasticity of marginal utility with respect to consumption (i.e., $-\frac{d \ln u^{\prime}(c)}{d \ln c}$ ) are equal or higher than one, and this typically implies that the income effect is weakly stronger than the substitution effect, leading to a perfectly inelastic or downward sloping labor supply curve. ${ }^{45}$ One could instead allow for home production with no income

\footnotetext{
${ }^{44}$ Caliendo et al. (2015) and Adao et al. (2017) allow for mobility across both sectors and regions and quantify the effect of the China shock at the level of US states rather than commuting zones. Their results also point to weak effects of trade shocks on mobility across regions. See also the discussion in footnote 15.

${ }^{45}$ With preferences $u(c, l)=\frac{c^{1-\sigma}}{1-\sigma}-\frac{l^{1+1 / \psi}}{1+1 / \psi}$, the labor supply elasticity is $\epsilon=\frac{\psi(1-\sigma)}{1+\psi \sigma}$. Standard estimates (e.g., Hall 2009) have $\sigma \geq 1$ and hence $\epsilon \leq 0-$ a downward sloping labor-supply curve, implying that em-
} 
effects on labor supply, but this runs counter to evidence pointing to the importance of income effects - see Blundell and MaCurdy (1999). To us, this suggests the need to entertain some kind of labor market friction that can generate involuntary unemployment in response to a negative trade shock.

\section{Conclusion}

We think of this paper as establishing a bridge between two separate literatures. On the one hand, a recent wave of empirical work exemplified most prominently by Autor et al. (2013) has shown that trade shocks have important distributional implications, but without deriving welfare effects. On the other hand, research surveyed in Costinot and Rodríguez-Clare (2014) shows how to quantify the welfare effects of trade for a wide class of gravity models, but with so far little to say about distributional implications. ${ }^{46}$ In this paper we extend the multi-sector gravity model of trade to allow for heterogeneous labor as in Roy (1951) and Lagakos and Waugh (2013) and with multiple groups of ex-ante identical workers as in Burstein et al. (2015), and use the resulting framework to derive a simple approach to computing group-level and aggregate welfare effects of trade shocks. We borrow the identification strategy proposed by Autor et al. (2013), but we use it here to estimate the model's key parameter governing the degree of labor heterogeneity and the distributional implications of trade shocks.

We use the model to quantify the welfare effects of the China shocks on groups in the United States defined by geography and education. We find that the average effect is positive, that some groups experience losses as high as five times the average gain, and that those groups tend to be concentrated in certain geographic regions. Although poorer groups tend to fare worse and hence between-group inequality increases, under

ployment would expand in the regions negatively affected by the China shock. We ran the same regression as in Section 4 but with the employment rate as dependent variable and got a coefficient of 0.00182 (with s.e. 0.00105 ), which would imply a labor supply elasticity of 0.75 . To get $\epsilon=0.75$, and appealing to Chetty, Guren, Manoli and Weber (2011) to set $\psi=0.82$ (the Frisch elasticity for total hours supplied), we would need to set $\sigma \approx 0.05$, which is implausibly low. If instead we used the Frisch elasticity for the extensive margin of labor supply in Chetty et al. (2011), $\psi=0.28$, then the required $\sigma$ would be even lower. If there is compensation for trade shocks then income effects would be weaker and one could get a higher labor supply elasticity - in the limit with perfect insurance $\epsilon=\psi$ and this labor-supply approach could explain the observed employment effects, but without any post-compensation distributional implications.

${ }^{46}$ The only mention of distributional implications in Costinot and Rodríguez-Clare (2014) is in regards to Burstein and Vogel (2016), which is limited to quantifying welfare effects among low and high skilled workers. 
plausible measures of inequality aversion social welfare still improves as a consequence of the China shock.

The question addressed in this paper is complex and our approach has obvious limitations. Most importantly, our analysis adheres to the tradition in the trade literature and uses a static model with a competitive labor market and a perfectly inelastic labor supply. Thus, we do not address some of the features that have been highlighted in the empirical literature, most importantly the effects on employment. As mentioned earlier, it seems useful to explore how allowing for some kind of labor-market friction could generate involuntary unemployment in response to a trade shock, as in Carrère et al. (2015) or Coşar et al. (2016). More research on this topic is clearly needed.

\section{References}

Adão, Rodrigo, 2016, “Worker Heterogeneity, Wage Inequality, and International Trade: Theory and Evidence from Brazil," working paper.

Adao, Rodrigo, Costas Arkolakis, and Federico Esposito, 2017, “Trade Openness, Agglomeration Effects, and Endogenous Labor Supply: Theory and Evidence," working paper.

Amiti, Mary, Mi Dai, Robert C. Feenstra, and John Romalis, 2017, “How did China’s WTO entry benefit US consumers?," NBER working paper.

Antras, Pol, Alonso de Gortari, and Oleg Itskhoki, 2016, "Inequality, costly redistribution and welfare in an open economy," Working Paper.

Arkolakis, Costas, Arnaud Costinot, and Andrés Rodríguez-Clare, 2012, “New Trade Models, Same Old Gains?," American Economic Review, 102 (1), 94-130.

Artuç, Erhan, Shubham Chaudhuri, and John McLaren, 2010, “Trade Shocks and Labor Adjustment: A Structural Empirical Approach,” American Economic Review, 100 (3), 1008-45. 
Atkin, David and Dave Donaldson, 2015, "Who is Getting Globalized? The Size and Implications of Intranational Trade Costs," working paper.

Atkinson, Anthony B., 1970, "On the measurement of inequality," Journal of Economic Theory, 2 (3), 244-263.

Autor, David H., David Dorn, and Gordon H. Hanson, 2013, "The China Syndrome: Local Labor Market Effects of Import Competition in the United States,” American Economic Review, 103 (6), 2121-68.

$\ldots, \ldots$, and _ , 2016, “The china shock: Learning from labor-market adjustment to large changes in trade," Annual Review of Economics, 8, 205-240.

_ , _ , _ , and Jae Song, 2014, “Trade Adjustment: Worker-Level Evidence,” The Quarterly Journal of Economics, 129 (4), 1799-1860.

Bai, Liang and Sebastian Stumpner, 2017, "Estimating the Price Effects of Globalization: The Case of US Imports from China," working paper.

Blundell, Richard and Thomas MaCurdy, 1999, "Labor supply: A review of alternative approaches," Handbook of Labor Economics, 3, 1559-1695.

Bombardini, Matilde and Francesco Trebbi, 2012, "Risk aversion and expected utility theory: an experiment with large and small stakes," Journal of the European Economic Association, 10 (6), 1348-1399.

Burstein, Ariel and Jonathan Vogel, 2016, "International trade, technology, and the skill premium," The Journal of Political Economy (forthcoming).

_ , Eduardo Morales, and Jonathan Vogel, 2015, "Accounting for changes in betweengroup inequality," unpublished manuscript, UCLA, Princeton and NYU.

Caliendo, Lorenzo and Fernando Parro, 2015, "Estimates of the Trade and Welfare Effects of NAFTA," Review of Economic Studies, 82 (1), 1-44.

_ , Maximiliano Dvorkin, and Fernando Parro, 2015, “The Impact of Trade on Labor Market Dynamics," NBER working paper. 
Carrère, Céline, Anja Grujovic, and Frédéric Robert-Nicoud, 2015, “Trade and frictional unemployment in the global economy," CEPR Discussion Paper No. DP10692.

Chetty, Raj, 2006, “A New Method of Estimating Risk Aversion,” The American Economic Review, 96 (5), 1821-1834.

_ , Adam Guren, Day Manoli, and Andrea Weber, 2011, "Are micro and macro labor supply elasticities consistent? A review of evidence on the intensive and extensive margins," The American Economic Review, 101 (3), 471-475.

Cockburn, John, Bernard Decaluwé, and Véronique Robichaud, 2008, “Trade liberalization and poverty: A CGE analysis of the 1990s experience in Africa and Asia," Poverty and Economic Policy Research Network.

Coşar, A Kerem, 2013, "Adjusting to Trade Liberalization: Reallocation and Labor Market Policies," working paper.

_ , Nezih Guner, and James Tybout, 2016, "Firm dynamics, job turnover, and wage distributions in an open economy,” The American Economic Review, 106 (3), 625-663.

Conley, Timothy G., 1999, “GMM estimation with cross sectional dependence,” Journal of Econometrics, 92 (1), 1-45.

Costinot, Arnaud and Andrés Rodríguez-Clare, 2014, "Trade Theory with Numbers: Quantifying the Consequences of Globalization," Handbook of International Economics, 4, 197.

_ and Jonathan Vogel, 2010, "Matching and Inequality in the World Economy,” Journal of Political Economy, 118 (4).

_ , Dave Donaldson, and Ivana Komunjer, 2012, "What Goods Do Countries Trade? A Quantitative Exploration of Ricardo's Ideas,” The Review of Economic Studies, 79 (2), 581-608.

Dauth, Wolfgang, Sebastian Findeisen, and Jens Suedekum, 2014, "The rise of the East and the Far East: German labor markets and trade integration," Journal of the European Economic Association, 12 (6), 1643-1675. 
Dekle, Robert, Jonathan Eaton, and Samuel Kortum, 2008, "Global Rebalancing with Gravity: Measuring the Burden of Adjustment," IMF Staff Papers, 55 (3), 511-540.

Dix-Carneiro, Rafael, 2014, “Trade liberalization and labor market dynamics," Econometrica, 82 (3), 825-885.

- and Brian Kovak, 2016, "Trade Reform and Regional Dynamics: Evidence from 25 Years of Brazilian Matched Employer-Employee Data," Working Paper.

Eaton, Jonathan and Samuel Kortum, 2002, “Technology, Geography, and Trade," Econometrica, 70 (5), 1741-1779.

Faber, Benjamin, 2014, “Trade Liberalization, the Price of Quality, and Inequality: Evidence from Mexican Store Prices," working paper.

Fajgelbaum, Pablo D. and Amit K. Khandelwal, 2016, "Measuring the unequal gains from trade," The Quarterly Journal of Economics, 131 (3), 1113-1180.

Goldberg, Pinelopi, “Introduction,” 2015, in Pinelopi Goldberg, ed., Trade and Inequality, Edward Elgar Research Collections.

Goldberg, Pinelopi Koujianou and Nina Pavcnik, 2007, "Distributional Effects of Globalization in Developing Countries," Journal of Economic Literature, 45, 39-82.

Hakobyan, Shushanik and John McLaren, 2016, "Looking for local labor market effects of NAFTA," Review of Economics and Statistics, 98 (4), 728-741.

Hall, Robert E., 2009, "Reconciling cyclical movements in the marginal value of time and the marginal product of labor," Journal of Political Economy, 117 (2), 281-323.

Head, Keith and Thierry Mayer, "Gravity Equations: Workhorse, Toolkit, and Cookbook,” 2014, in “Handbook of International Economics,” Vol. 4 pp. 131 - 195.

Helpman, Elhanan, Oleg Itskhoki, Marc-Andreas Muendler, and Stephen J Redding, 2017, "Trade and inequality: From theory to estimation," The Review of Economic Studies, 84 (1), 357-405.

Hsiang, Solomon M., 2010, “Temperatures and cyclones strongly associated with economic production in the Caribbean and Central America," Proceedings of the National Academy of sciences, 107 (35), 15367-15372. 
Hsieh, Chang-Tai and Ralph Ossa, 2011, "A global view of productivity growth in China.”

_ and _ , 2016, "A global view of productivity growth in China," Journal of International Economics, 102, $209-224$.

_ , Erik Hurst, Charles I. Jones, and Peter J. Klenow, 2013, “The Allocation of Talent and U.S. Economic Growth,” NBER Working Paper.

Jones, Charles I and Peter J Klenow, 2016, “Beyond GDP? Welfare across countries and time,” The American Economic Review, 106 (9), 2426-2457.

Kambourov, Gueorgui, 2009, "Labour market regulations and the sectoral reallocation of workers: The case of trade reforms," The Review of Economic Studies, 76 (4), 13211358.

Kovak, Brian K., 2013, "Regional Effects of Trade Reform: What is the Correct Measure of Liberalization?," The American Economic Review, 103 (5), 1960-1976.

Krishna, Pravin, Jennifer P. Poole, and Mine Zeynep Senses, 2012, “Trade, Labor Market Frictions, and Residual Wage Inequality across Worker Groups," American Economic Review, 102 (3), 417-23.

Lagakos, David and Michael E. Waugh, 2013, "Selection, Agriculture, and CrossCountry Productivity Differences," The American Economic Review, 103 (2), 948-980.

Layard, Richard, Guy Mayraz, and Stephen Nickell, 2008, "The marginal utility of income," Journal of Public Economics, 92 (8), 1846-1857.

Lee, Eunhee, 2016, “Trade, Inequality, and the Endogenous Sorting of Heterogeneous Workers," Working Paper.

Lucas, Robert E., 2003, “Macroeconomic Priorities,” American Economic Review, 93 (1), $1-14$.

Monte, Ferdinando, Stephen J Redding, and Esteban Rossi-Hansberg, 2015, "Commuting, migration and local employment elasticities," NBER working paper.

Paravisini, Daniel, Veronica Rappoport, and Enrichetta Ravina, 2016, "Risk aversion and wealth: Evidence from person-to-person lending portfolios," Management Science, 63 (2), 279-297. 
Pierce, Justin R. and Peter K. Schott, 2016, “The surprisingly swift decline of US manufacturing employment," The American Economic Review, 106 (7), 1632-1662.

Porto, Guido G., 2006, "Using survey data to assess the distributional effects of trade policy," Journal of International Economics, 70 (1), 140-160.

Rawls, John, Justice as fairness: A restatement, Harvard University Press, 2001.

Revenga, Ana L., 1992, "Exporting jobs? The impact of import competition on employment and wages in US manufacturing," The Quarterly Journal of Economics, pp. 255284.

Roy, Andrew Donald, 1951, "Some thoughts on the distribution of earnings," Oxford economic papers, 3 (2), 135-146.

Timmer, Marcel P, Erik Dietzenbacher, Bart Los, Robert Stehrer, and Gaaitzen J Vries, 2015, "An illustrated user guide to the world input-output database: the case of global automotive production," Review of International Economics, 23 (3), 575-605.

Topalova, Petia, 2010, "Factor Immobility and Regional Impacts of Trade Liberalization: Evidence on Poverty from India," American Economic Journal: Applied Economics, 2 (4), 1-41.

Yi, Moises, Steffen Müller, and Jens Stegmaier, 2016, "Industry Mix, Local Labor Markets, and the Incidence of Trade Shocks," working paper. 


\section{Appendix A Background Tables and Figures}

Table A.1: List of Sectors

\begin{tabular}{llcccc}
\hline Sector Nr. & Sector description & $\beta_{s}$ & $r_{s}$ & $\beta_{s} / r_{s}$ & $\lambda_{U S, U S, s}$ \\
\hline $15-16$ & Food, Beverages and Tobacco & 0.03 & 0.03 & 0.98 & 0.95 \\
$17-19$ & Textiles and Textile or Leather Products & 0.01 & 0.01 & 1.51 & 0.57 \\
20 & Wood and Products of Wood and Cork & 0.01 & 0.01 & 1.09 & 0.86 \\
$21-22$ & Pulp, Paper, Printing and Publishing & 0.02 & 0.02 & 0.98 & 0.94 \\
23 & Coke, Refined Petroleum and Nuclear Fuel & 0.01 & 0.01 & 1.03 & 0.91 \\
24 & Chemicals and Chemical Products & 0.02 & 0.02 & 1.01 & 0.82 \\
25 & Rubber and Plastics & 0.01 & 0.01 & 1.01 & 0.89 \\
26 & Other Non-Metallic Mineral & 0.01 & 0.01 & 1.06 & 0.85 \\
$27-28$ & Basic Metals and Fabricated Metal & 0.03 & 0.02 & 1.05 & 0.86 \\
29 & Machinery, Nec & 0.02 & 0.02 & 0.94 & 0.75 \\
$30-33$ & Electrical and Optical Equipment & 0.04 & 0.04 & 1.07 & 0.62 \\
$34-35$ & Transport Equipment & 0.04 & 0.03 & 1.06 & 0.73 \\
$36-37$ & Manufacturing, Nec; Recycling & 0.01 & 0.01 & 1.26 & 0.67 \\
& Non-manufacturing & 0.75 & 0.76 & 0.99 & 0.98 \\
\hline
\end{tabular}

This table lists the 14 sectors used in our analysis. The first column has the ISIC Rev.3 sectors for each of the manufacturing subsectors, and the second column has the sector description. The next three columns show the Cobb-Douglas expenditure share, the earnings share $r_{s}$ and the sectoral import-competition index $\beta_{s} / r_{s}$ for the US. The final column has the domestic expenditure share for the US, $\lambda_{U S, U S, s}$. 
Table A.2: Estimation of $\kappa$ on sample including part-time workers

\begin{tabular}{lccc}
\hline \hline & \multicolumn{3}{c}{ Dependent variable: $\ln \hat{y}_{g}$} \\
Definition of $\pi_{g s}$ & Workers & Hours & Earnings \\
\hline \hline $\ln \hat{\pi}_{g N M}$ & -0.615 & -0.634 & -0.639 \\
& $(0.156)$ & $(0.165)$ & $(0.183)$ \\
\hline Implied $\kappa$ & 1.625 & 1.577 & 1.564 \\
& $(0.412)$ & $(0.411)$ & $(0.448)$ \\
First-stage F-Statistic & 25.67 & 21.35 & 10.15 \\
Observations & 1444 & 1444 & 1444 \\
\hline \hline
\end{tabular}

This table presents a robustness check for the estimation results in Table 2, using a sample that also includes part-time workers. The results are from an IV-estimation of specification (20), where $y_{g}$ is average earnings per worker, and $\pi_{g N M}$ is the labor share employed in non-manufacturing. Labor shares $\pi_{g s}$ are measured as the share of workers, share of labor hours and share of earnings for columns 1, 2 and 3 respectively. Standard errors (in parentheses) are calculated as in Conley (1999), with a cutoff for the spatial correlation at approximately $400 \mathrm{~km}$. The first row shows the second-stage results, while the fourth row has the corresponding $\kappa$ estimates implied by the model and the sixth row displays the F-statistic from the first stage. 
Figure A.1: Distribution of the welfare gains from the rise of China

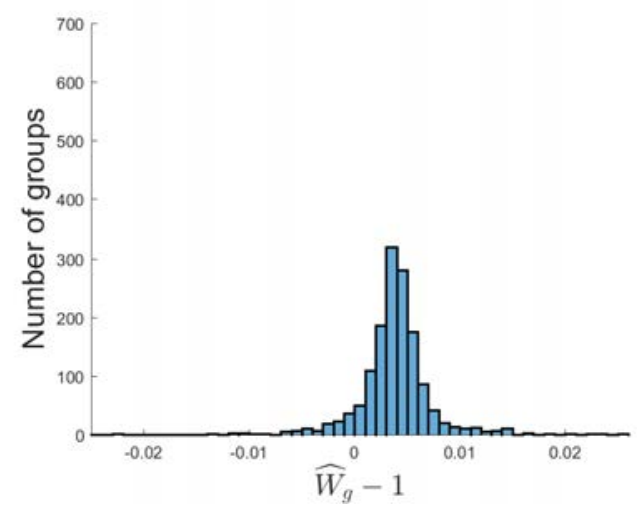

(a) $\kappa \rightarrow 1$

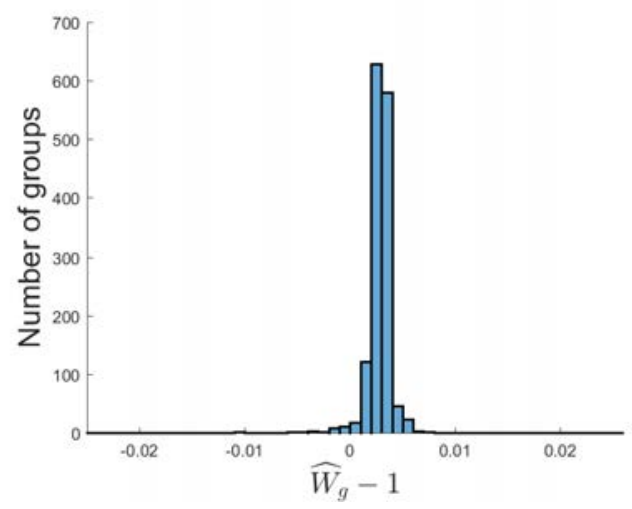

(c) $\kappa=4$

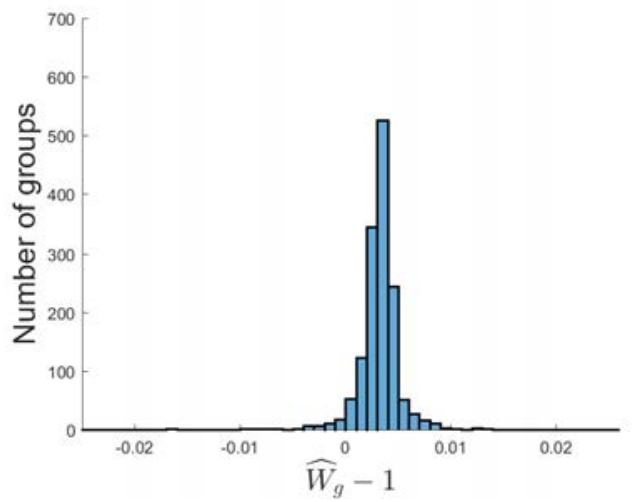

(b) $\kappa=2$

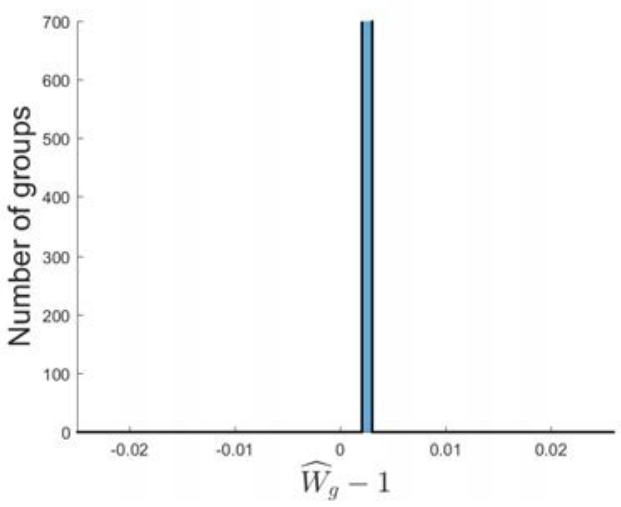

(d) $\kappa \rightarrow \infty$

This figure plots the distribution of $\hat{W}_{g}-1$, where $\hat{W}_{g}$ are the welfare effects for all US groups from the counterfactual rise of China. The different panels show the welfare results for different values of $\kappa$, indicated at the bottom of each panel. The vertical axis counts the number of groups in each bin, and the total number of groups is 1444. For visual reasons, the scale of the vertical axis is censored at 700. 
Table A.3: The Welfare Effects of the China Shock on the US

\begin{tabular}{ccccccc}
\hline$\kappa$ & $\widehat{W}_{U S}$ & Mean & CV & Min. & Max. & $\prod_{s} \widehat{\lambda}_{s}^{-\beta_{s} / \theta_{s}}$ \\
\hline$\rightarrow 1$ & 0.27 & 0.41 & 0.86 & -3.24 & 2.59 & 0.20 \\
2 & 0.25 & 0.32 & 0.56 & -1.64 & 1.34 & 0.20 \\
4 & 0.23 & 0.27 & 0.34 & -0.76 & 0.74 & 0.21 \\
$\rightarrow \infty$ & 0.22 & 0.22 & 0 & 0.22 & 0.22 & 0.22 \\
\hline
\end{tabular}

Compared to Table 3 , here the values for $\hat{T}_{C h i n a, s}$ are separately calibrated for each value of $\kappa$. The first column displays the aggregate welfare effect of the China shock for the US, in percentage terms $\left(100\left(\widehat{W}_{U S}-1\right)\right.$, and the second column shows the mean welfare effect: $100\left(\frac{1}{G} \sum_{g} \widehat{W}_{U S, g}-1\right)$. The third column shows the coefficient of variation (CV), and for the fourth and fifth column we have Min. $\equiv \min _{g} 100\left(\widehat{W}_{U S, g}-1\right)$ and Max. $\equiv \max _{g} 100\left(\widehat{W}_{U S, g}-1\right)$, respectively. The final column displays $100\left(\prod_{s} \widehat{\lambda}_{U S, U S, s}^{-\beta_{U S, s} / \theta_{s}}-1\right)$.

Figure A.2: Changes in import competition and groups' relative income for the China shock

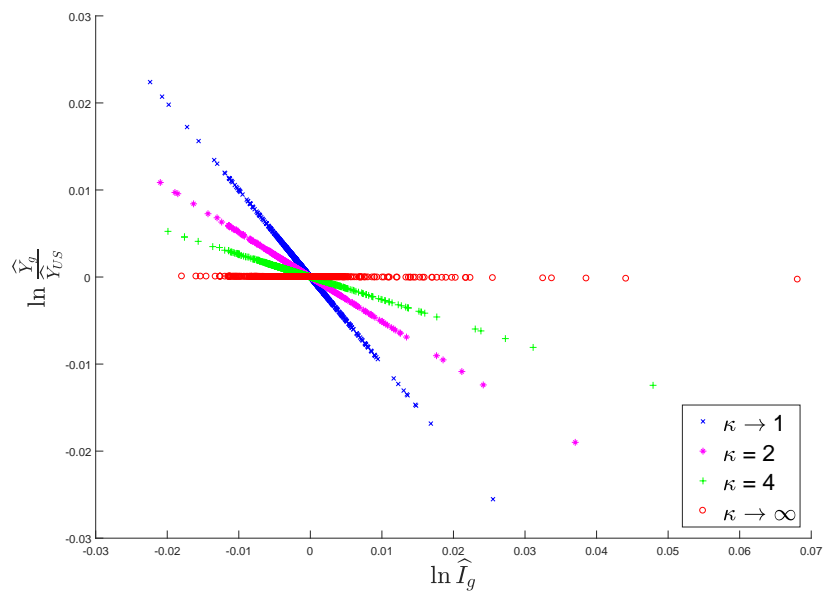

The figure plots the value for $\ln \frac{\hat{Y}_{g}}{\hat{Y}_{U S}}$ in relation to $\ln \hat{I}_{g}=-\ln \sum_{s} \pi_{g s} \hat{r}_{s}$, our Bartik measure for the change in groups' import-competition. Each scatter represents the simulation results for a different value of $\kappa$, for values of $\hat{T}_{C h i n a, s}$ calibrated for $\kappa=2$. 
Figure A.3: Distribution of the Gains from Trade

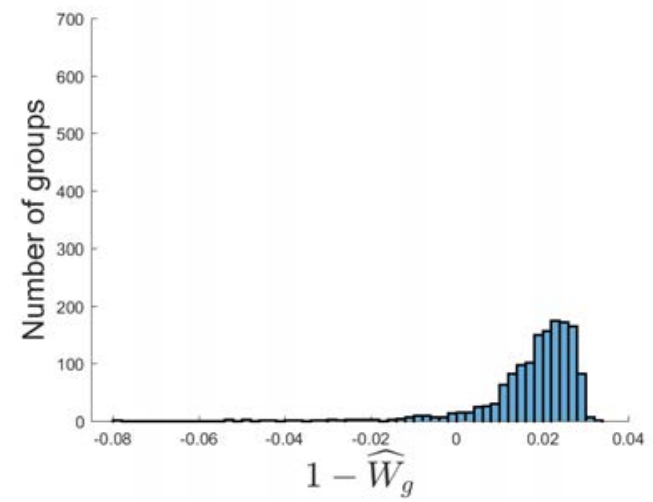

(a) $\kappa \rightarrow 1$

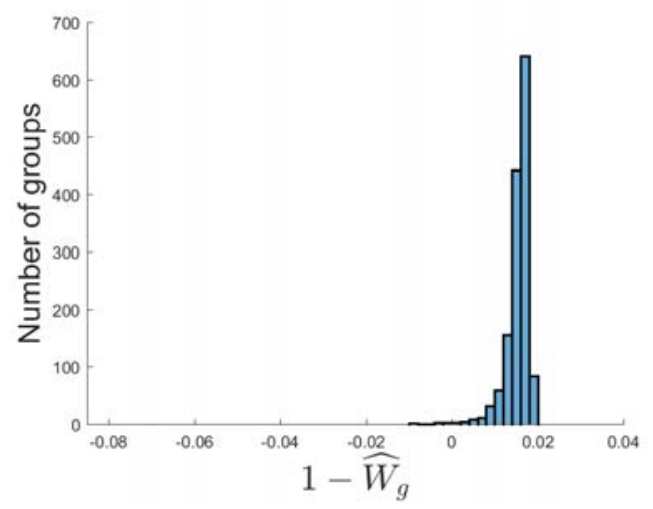

(c) $\kappa=4$

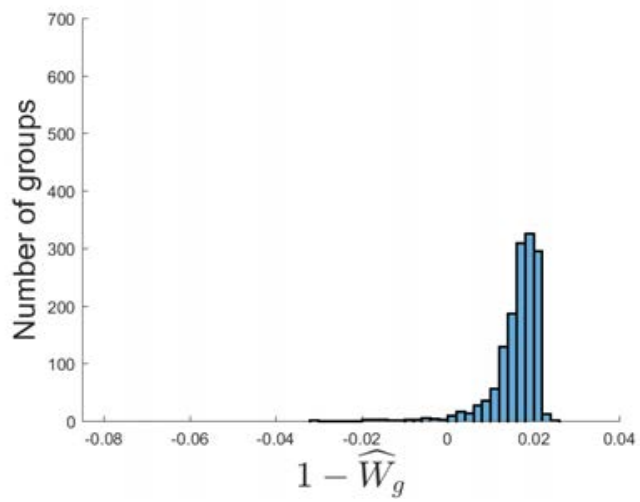

(b) $\kappa=2$

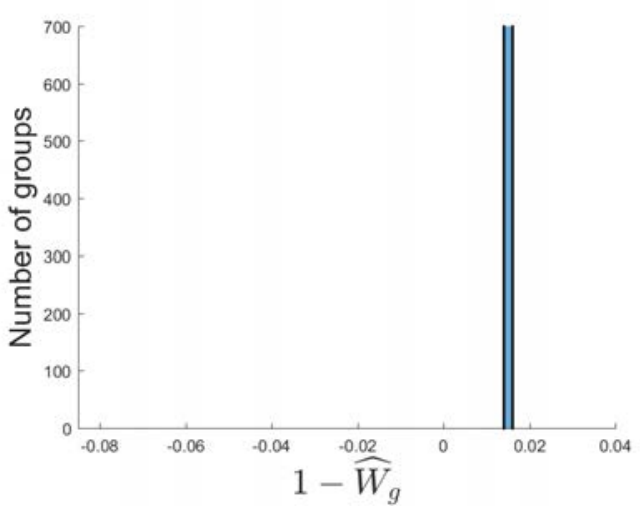

(d) $\kappa \rightarrow \infty$

This figure plots the distribution of $1-\hat{W}_{g}$, where $\hat{W}_{g}$ are the welfare effects for all US groups from a return to autarky. The different panels show the welfare results for different values of $\kappa$, indicated at the bottom of each panel. The vertical axis counts the number of groups in each bin, and the total number of groups is 1444 . For visual reasons, the scale of the vertical axis is censored at 700 . 
Figure A.4: China Shock and Initial Income - WIOD Measures

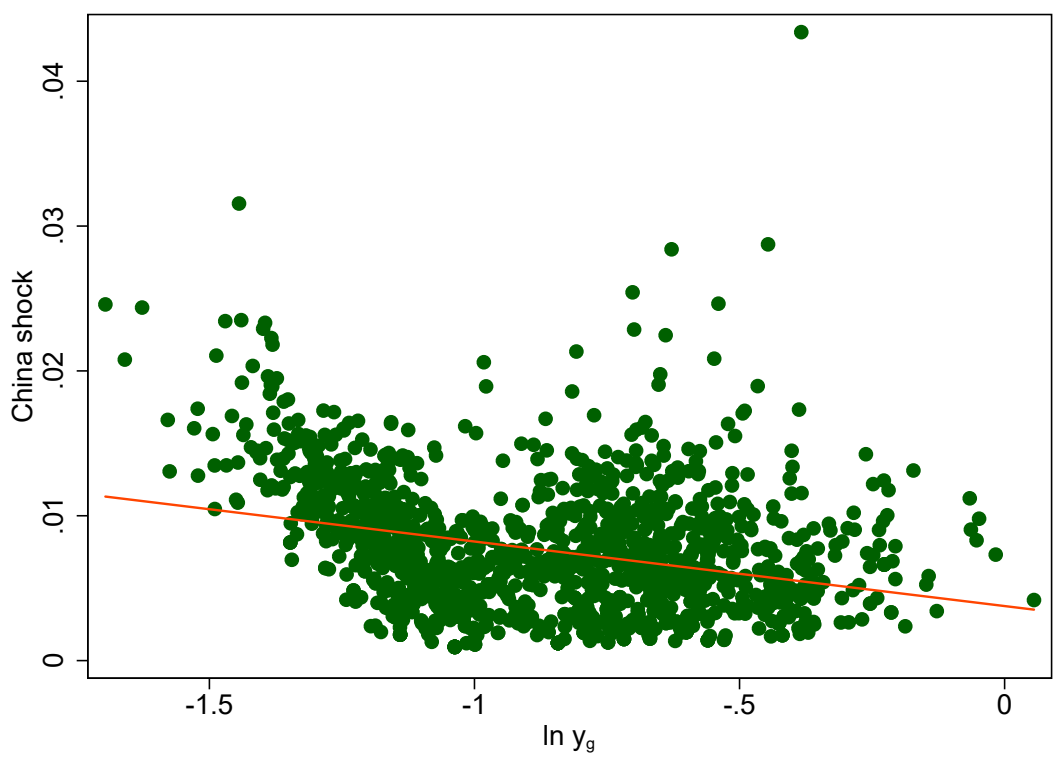

The figure plots the China shock against initial log income $\ln y_{g}$, where the former is defined as $\sum_{s \in M} \pi_{g s} \Delta I P_{s}^{C h i n a \rightarrow O t h e r}$. $\ln y_{g}$ and $\pi_{g s}$ are model-adjusted for compatibility with WIOD. The line plots the linear fit through the scatter.

Figure A.5: China Shock and Initial Income - Census/ACS Measures

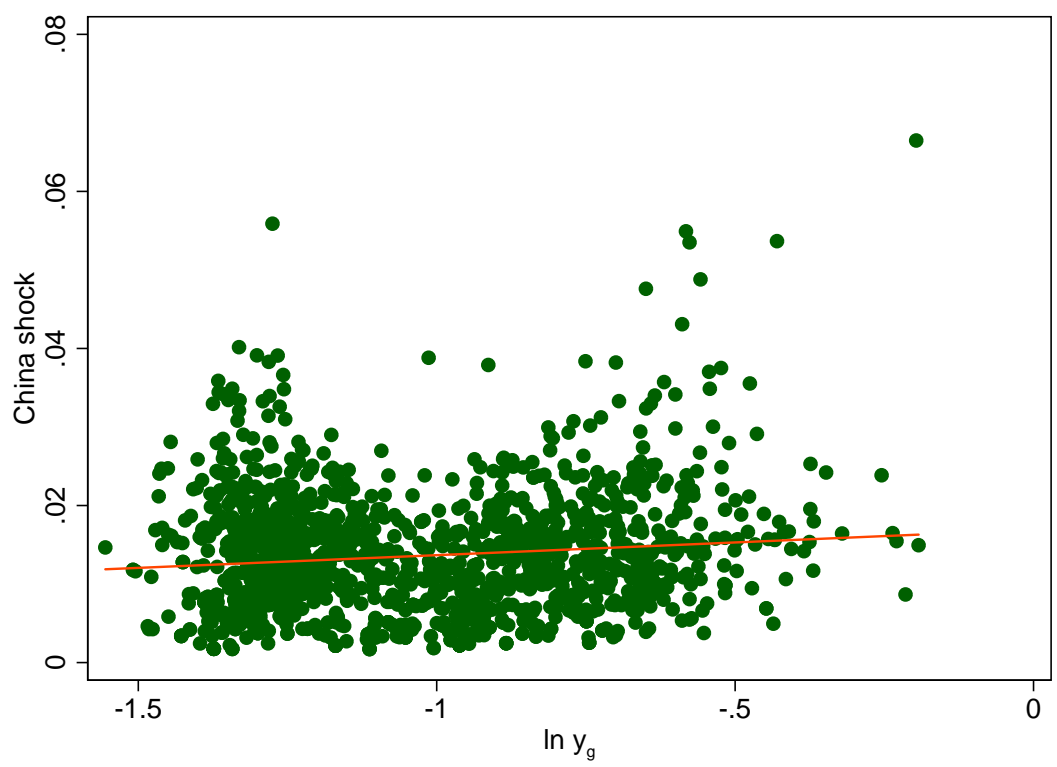

The figure plots the China shock against initial $\log$ income $\ln y_{g}$, where the former is defined as $\sum_{s \in M} \pi_{g s} \Delta I P_{s}^{\text {China } \rightarrow \text { Other }}$. $\ln y_{g}$ and $\pi_{g s}$ are based on Census/ACS data. The line plots the linear fit through the scatter. 
Figure A.6: Import competition and groups' relative gains from return to autarky

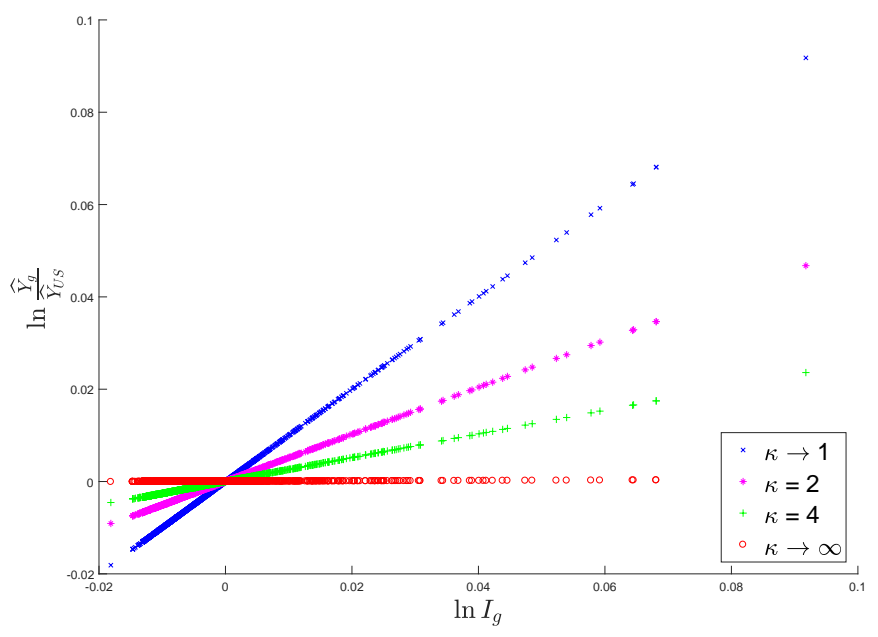

The figure plots the value for $\ln \frac{\hat{Y}_{g}}{\hat{Y}_{U S}}$ in relation to $\ln I_{g}=\frac{\beta_{i s}}{r_{i s}}$, our Bartik measure for groups' importcompetition. Each scatter represents the simulation results for the return to autarky for a different value of $\kappa$. 
Figure A.7: Geographical Distribution of the Gains from Trade

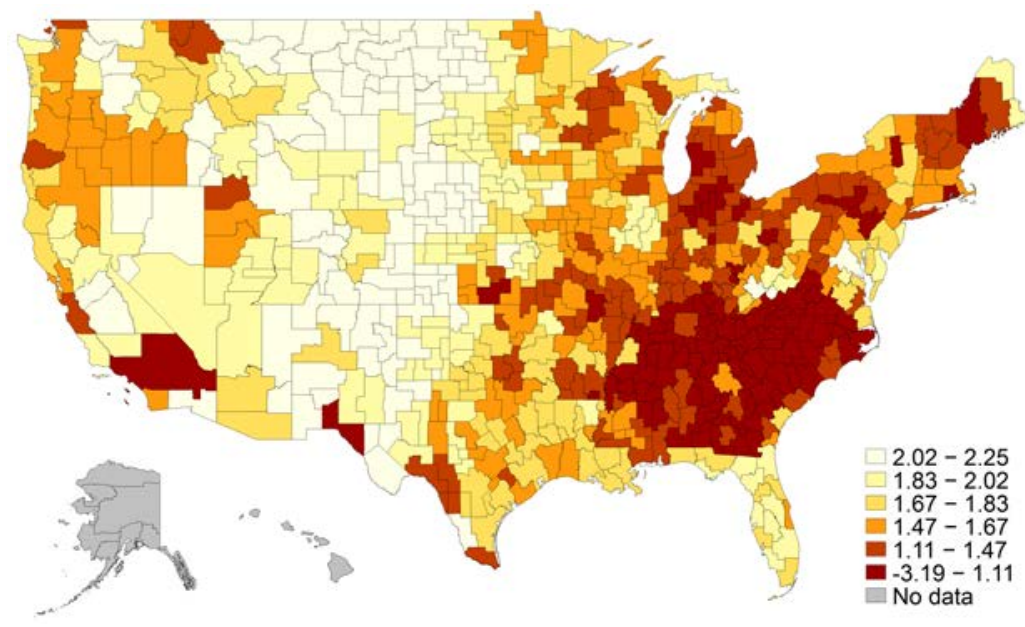

(a) Low-educated workers

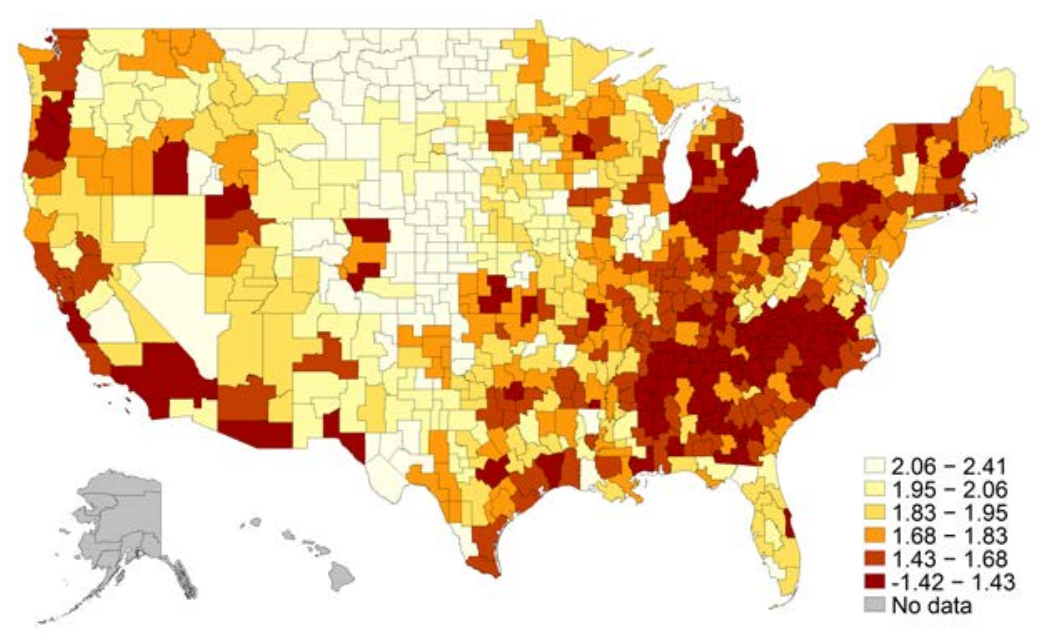

(b) High-educated workers

This figure plots the geographic distribution of $100\left(1-\hat{W}_{g}\right)$, where $\hat{W}_{g}$ are the welfare effects for group g in the US from a return to autarky for our preferred value of $\kappa=2$. Panel (a) and (b) display results for the low-educated and high-educated groups respectively. 
Figure A.8: Group-level Import Competition and Income - Census/ACS Measures

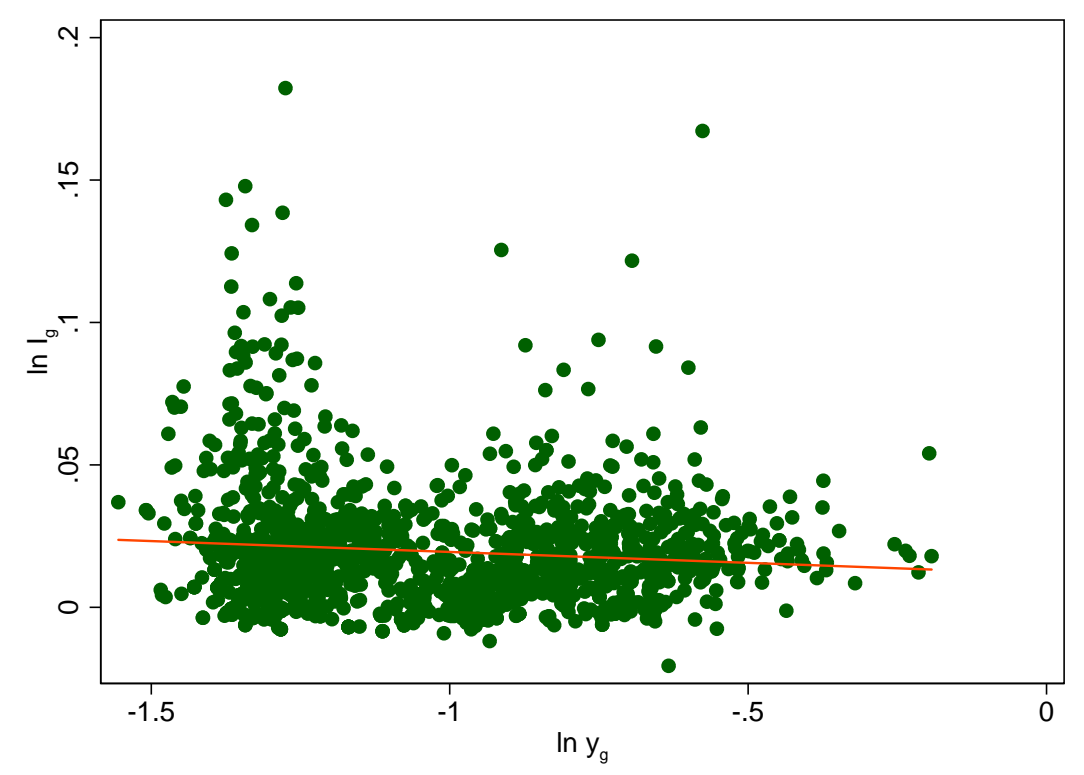

The figure plots the relationship between $\ln I_{g} \equiv \ln \sum_{s} \pi_{i g s} \frac{\beta_{i s}}{r_{i s}}$, our measure for regional importcompetition, and the logarithm of group-level average income per worker. $\ln y_{g}$ and $\pi_{g s}$ are based on Census/ACS data. The line plots the linear fit through the scatter. 
Figure A.9: Comparison of the baseline model and the model with intermediate goods

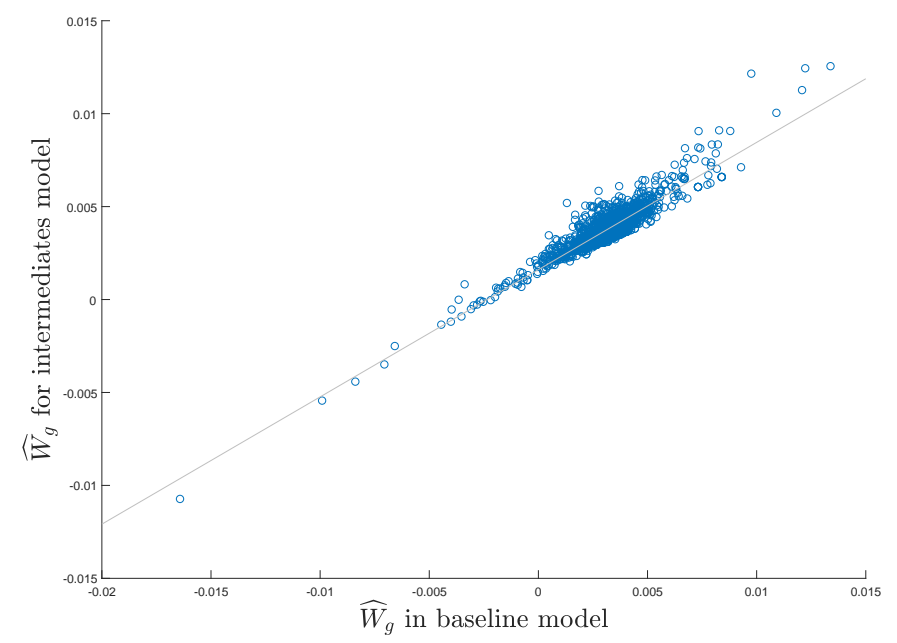

(a) The rise of China

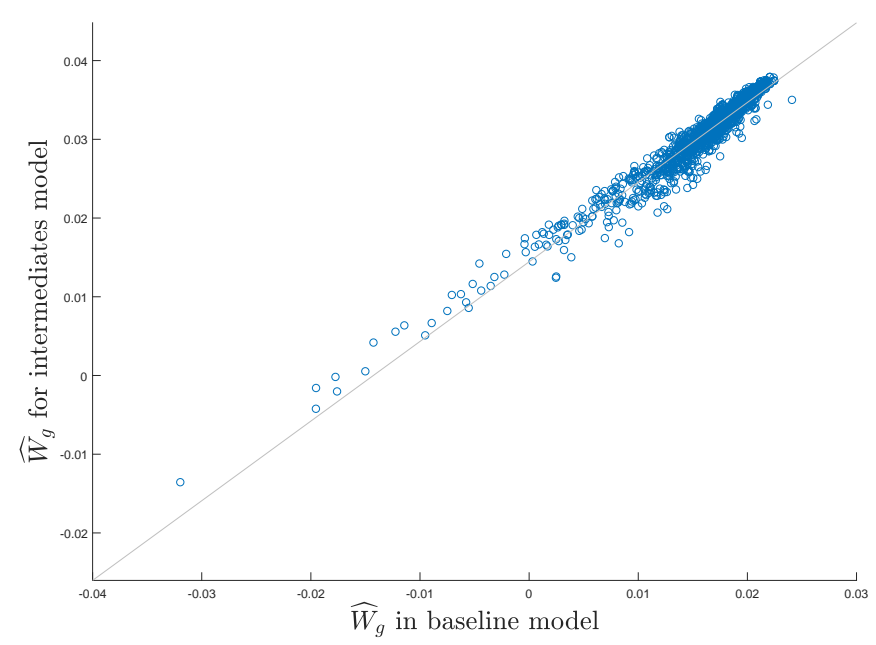

(b) Gains from trade

This figure compares the welfare changes for the two models, showing $\widehat{W}_{g}-1$ for the rise of China, and $1-\widehat{W}_{g}$ for the return to autarky. 
Figure A.10: Comparison of baseline model with the model where US states are countries

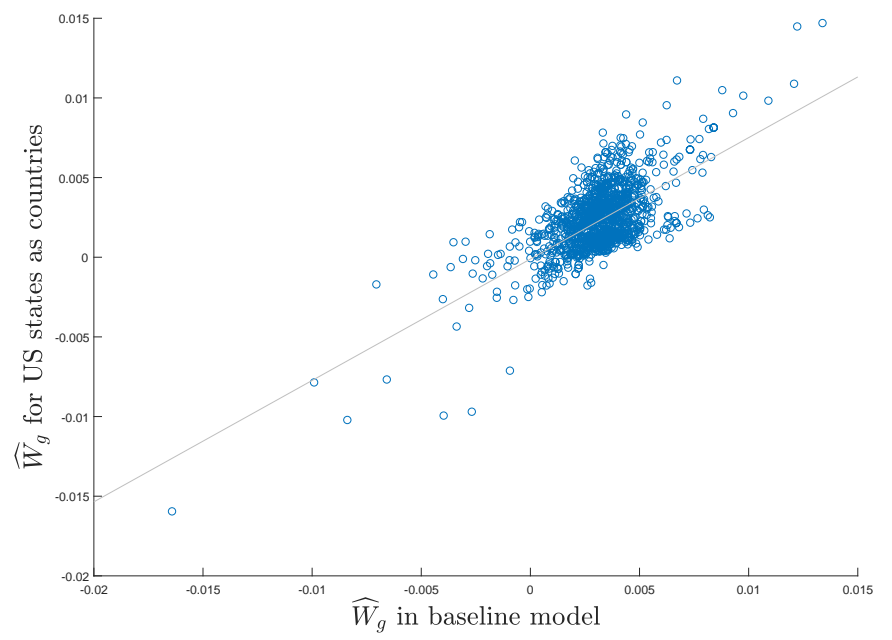

(a) The rise of China

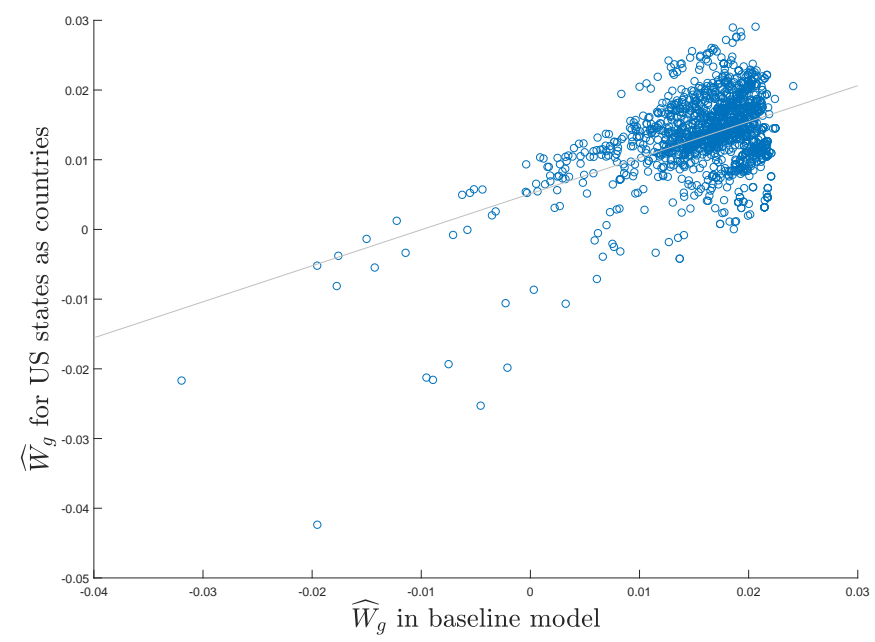

(b) Gains from trade

This figure compares the welfare changes for the two models, showing $\widehat{W}_{g}-1$ for the rise of China, and $1-\widehat{W}_{g}$ for the return to autarky. 
Figure A.11: Geographical distribution of the welfare gains from the rise of China with costly within-US trade

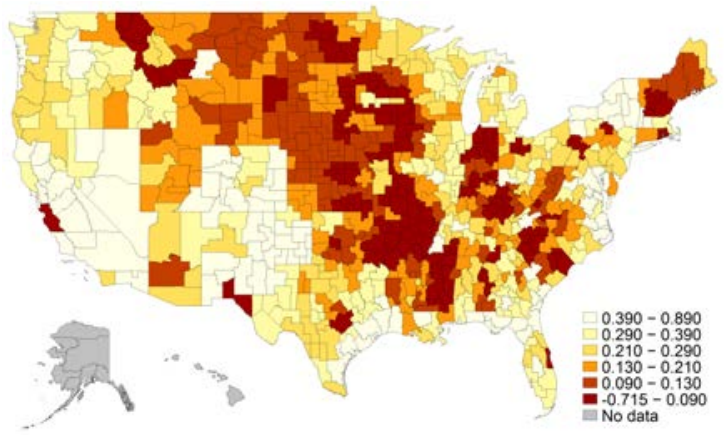

(a) $\hat{W}_{n g}$ for low-educated workers

(c) $\hat{W}_{n g}$ for high-educated workers

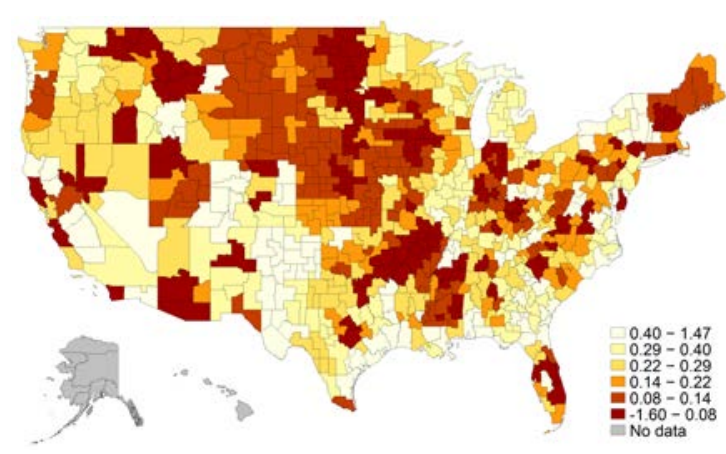

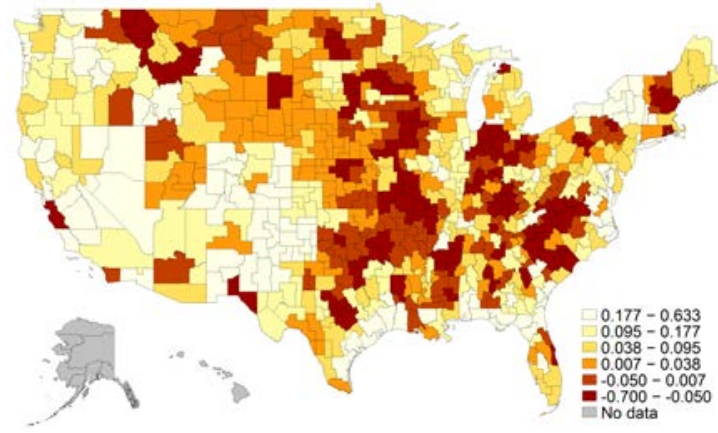

(b) $\prod_{s} \hat{\pi}_{i g s}^{-\beta_{n s} / \kappa}$ for low-educated workers

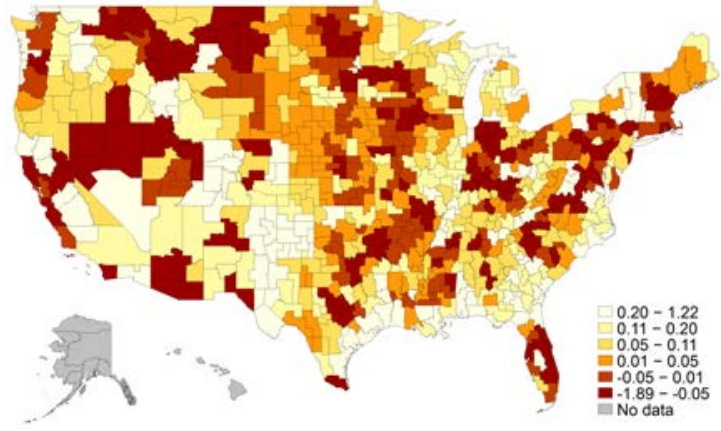

(d) $\prod_{s} \hat{\pi}_{i g s}^{-\beta_{n s} / \kappa}$ for high-educated workers

This figure plots the geographic distribution of the group-level welfare effects and the group-level Roy terms resulting from the China shock for the model with costly within-US trade, for our preferred value of $\kappa=2$. Panels (a) and (c) plot welfare effects $100\left(\hat{W}_{g}-1\right)$, and panels (b) and (c) plot the group's Roy terms $100\left(\prod_{s} \pi_{i g s}^{-\beta_{n} s / \kappa}-1\right)$. Panels (a) and (b) display results for low-educated groups, while Panels (c) and (d) show results for high-educated groups. 
Figure A.12: Geographical distribution of the gains from trade with costly within-US trade

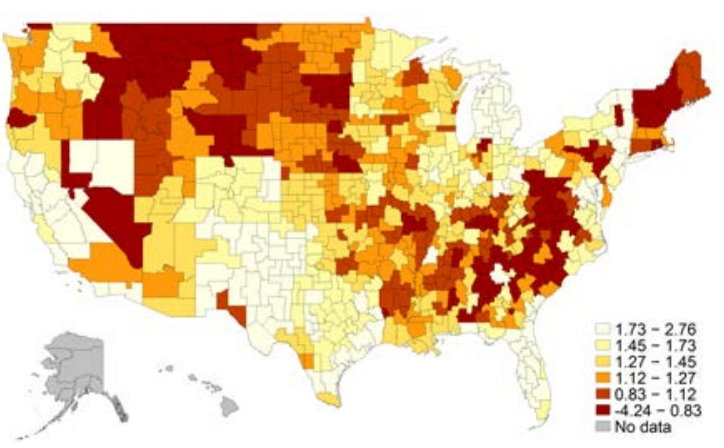

(a) $\hat{W}_{n g}$ for low-educated workers

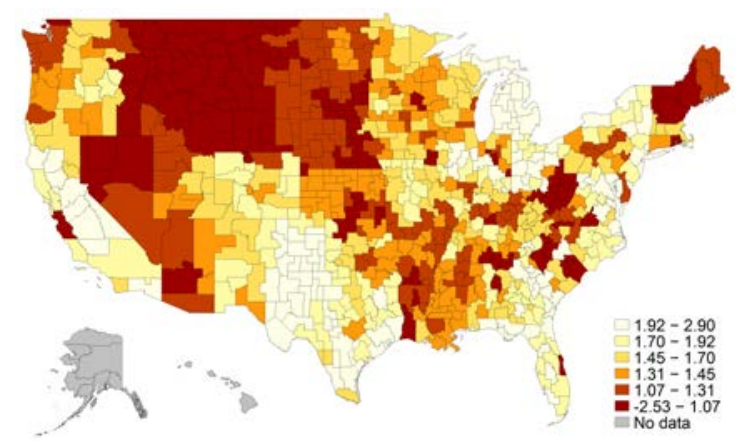

(c) $\hat{W}_{n g}$ for high-educated workers

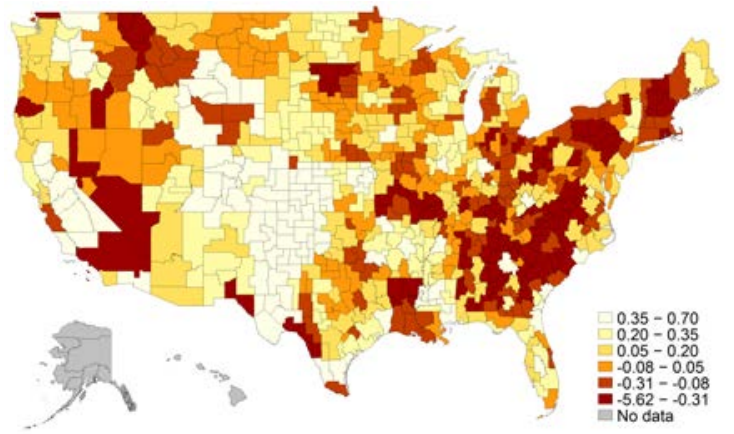

(b) $\prod_{s} \hat{\pi}_{i g s}^{-\beta_{n s} / \kappa}$ for low-educated workers

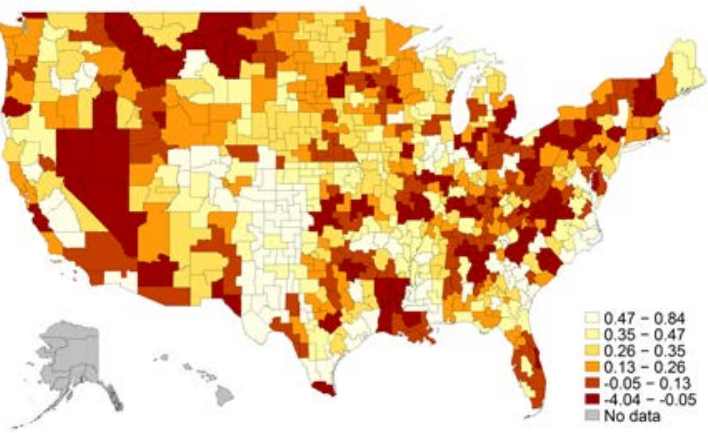

(d) $\prod_{s} \hat{\pi}_{i g s}^{-\beta_{n s} / \kappa}$ for high-educated workers

This figure plots the geographic distribution of the group-level gains from trade and the associated grouplevel Roy terms for the model with costly within-US trade, for our preferred value of $\kappa=2$. Panels (a) and (c) plot welfare effects $100\left(1-\hat{W}_{g}\right)$, and panels (b) and (c) plot the group's Roy terms $100\left(1-\prod_{s} \pi_{i g s}^{-\beta_{n s} / \kappa}\right)$, where the hat variables are obtained from the simulated return to autarky. Panels (a) and (b) display results for low-educated groups, while Panels (c) and (d) shows results for high-educated groups. 


\section{Appendix B Data description}

Our group-level labor market data is obtained from the 2000 Census and American Community Survey (ACS) ${ }^{47}$ Both datasets are downloaded from IPUMS using standardized variables. Our labor market data for the year 2000 is derived from a $5 \%$ sample of the 2000 Census. For the year 2011, labor market figures are based on ACS data. We exclude unpaid family workers, and employees that work in non-profits or any branch of the government (i.e. federal, state or local governments or the armed forces). We also exclude data from Alaska and Hawaii. Our measure of earnings includes all earned income over the past 12 months.

For the model extension on costly within-US trade in Section 7.2, we use data from the Commodity Flow Survey (CFS). Since the CFS is only collected every five years, we use the CFS from 2002 and 2012 for the first and second period respectively. Using the CFS, we construct trade data between all US states and all other countries in the WIOD sample. To this end, we use the variable $X_{n m s}^{C F S}$, which denotes exports from state $n$ to state $m$ in sector $s$, as observed in the CFS.

First, in order to construct exports of US states to other WIOD countries define state-level production in sector $s$ as $Y_{n s}^{C F S} \equiv \sum_{m \in U S} X_{n m s}^{C F S}$ and calculate production shares as

$$
\mu_{n s} \equiv \frac{Y_{n s}^{C F S}}{\sum_{m \in U S} Y_{m s}^{C F S}} .
$$

Next, let $X_{U S j s}^{W I O D}$ be the exports from the US to destination country $j$ in sector $s$, observed in WIOD. We then infer exports from state $n$ to destination country $j$ in sector $s$ as

$$
X_{n j s}=\mu_{n s} X_{U S j s}^{W I O D}
$$

Second, in order to construct imports of US states from other WIOD countries, define state-level expenditures in sector $s$ as $E_{m s}^{C F S} \equiv \sum_{n \in U S} X_{n m s}^{C F S}$ and construct expenditure shares as

$$
\theta_{m s} \equiv \frac{E_{m s}^{C F S}}{\sum_{n \in U S} E_{n s}^{C F S}}
$$

\footnotetext{
${ }^{47}$ The ACS is designed to be comparable to the Census.
} 
We then infer imports from state $m$ from origin country $i$ in sector $s$ as

$$
X_{i m s}=\theta_{m s} X_{i U S s}^{W I O D}
$$

Finally, to construct exports and imports vis-a-vis other states, we need to scale the CFS flows to match the WIOD trade values. To this end, define the "intra-US trade factor" as

$$
f_{s} \equiv \frac{X_{U S U S s}}{\sum_{n \in U S} Y_{n s}^{C F S}}
$$

We infer exports from state $n$ to state $m$ in sector $s$ as

$$
X_{n m s}=f_{s} X_{n m s}^{C F S}
$$


Figure B.1: Comparison of Group-level $\pi_{g s}$ Measures
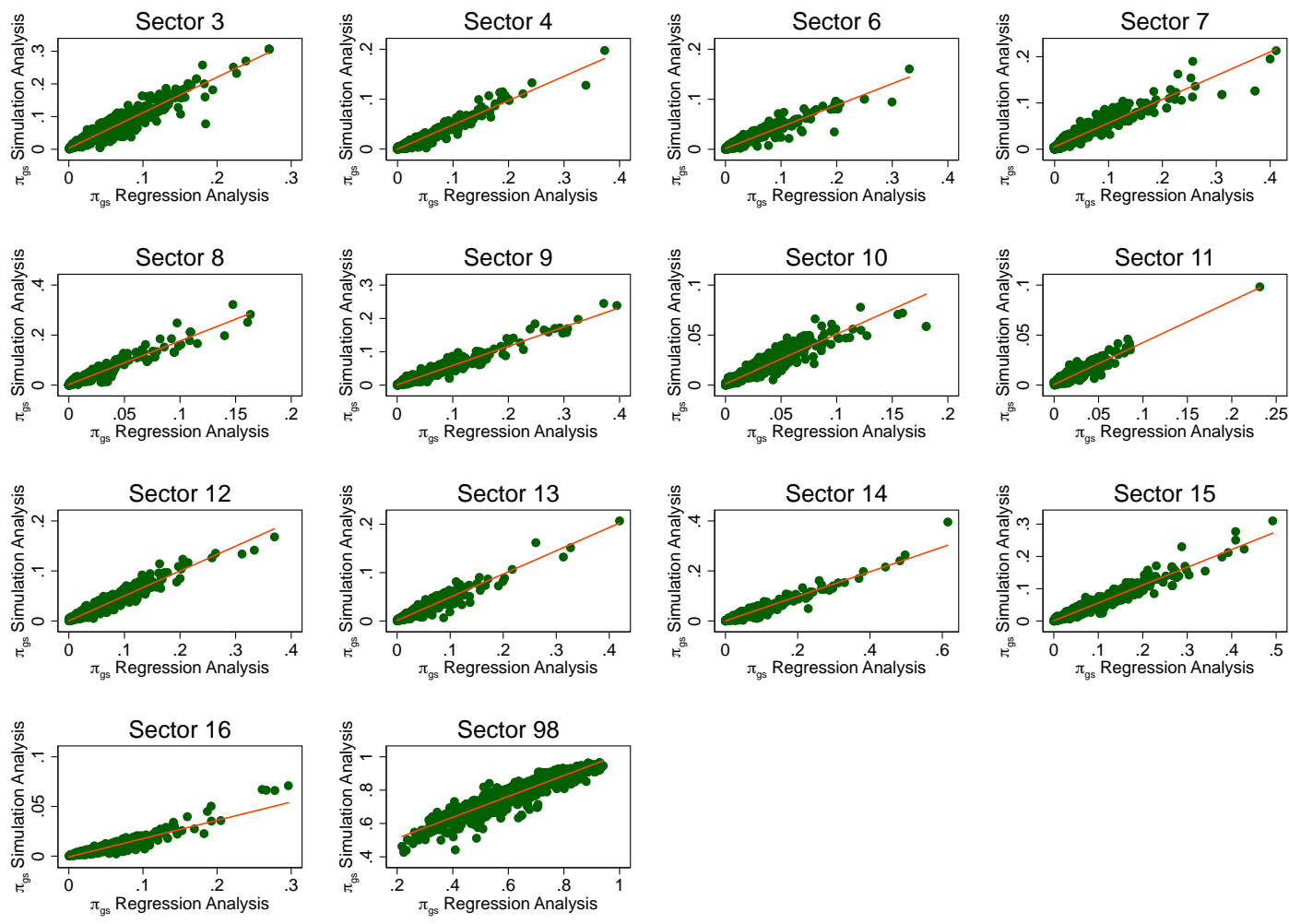

These figures compare, for each sector, the group-level earning shares measures employed in the regression and simulation analysis (described on Section 3). The horizontal axis displays the measures employed in the regression analysis (based on Census and ACS data). The vertical axis corresponds to the analogous measures employed in the simulation analysis (based on WIOD data). All measures are for the initial period (year 2000). 
Figure B.2: Comparison of Group-level Income Measures

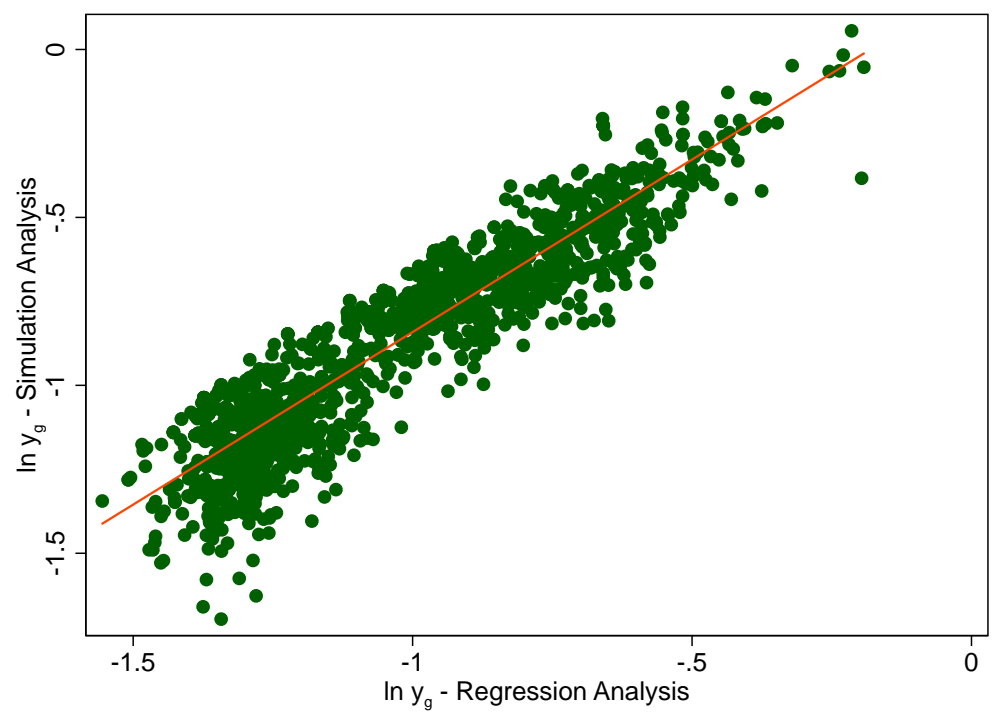

This figure compares the group-level income measures employed in the regression and simulation analysis (described on Section 3). The horizontal axis displays the measure of initial income per worker (year 2000) employed in the regression analysis (based on Census and ACS data). The vertical axis corresponds to the analogous income measure employed in the simulation analysis (based on WIOD data). The correlation coefficient between the two measures is 0.92 . 


\section{Appendix C Proof for Proposition 2}

We want to show that the aggregate gains from trade are higher when $\kappa_{i g}=\kappa<\infty$ than when $\kappa_{i g} \rightarrow \infty$ for all $g \in G_{i}$. Given the definition of the gains from trade, and using Equation (13), we must show that $\sum_{g \in G_{i}}\left(Y_{i g} / Y_{i}\right) \prod_{s} \hat{\pi}_{i g s}^{-\beta_{i s} / \kappa}<1$, or using $y_{i g} \equiv Y_{i g} / Y$ and Equation (10),

$$
\sum_{g} y_{i g} \prod_{s}\left(\hat{w}_{i s}\left(\sum_{k} \pi_{i g k} \hat{w}_{k}^{\kappa}\right)^{-1 / \kappa}\right)^{-\beta_{i s}}<1 .
$$

Rewriting this equation as $\sum_{g \in G_{i}} y_{i g}\left(\sum_{k} \pi_{i g k} \hat{w}_{i k}^{\kappa}\right)^{1 / \kappa}<\prod_{s} \hat{w}_{i s}^{\beta_{i s}}$, we can write what we want to show as

$$
\sum_{g \in G_{i}} y_{i g} x_{i g}<\prod_{s} \hat{w}_{i s}^{\beta_{i s}}
$$

where $x_{i g} \equiv\left(\sum_{s} \pi_{i g s} \hat{w}_{i s}^{\kappa}\right)^{1 / \kappa}$, and where, from Equation (14), $\hat{w}_{i s}$ is given by the solution of

$$
\beta_{i s} \sum_{g \in G_{i}} x_{i g} y_{i g}=\sum_{g \in G_{i}} \hat{w}_{i s}^{\kappa} x_{i g}^{1-\kappa} \pi_{i g s} y_{i g} \text { for } s=1, \ldots, S .
$$

Solving for $\hat{w}_{i s}$ from this equation and plugging into the inequality above we see that we need to prove that

$$
\left(\sum_{g} y_{i g} x_{i g}\right)^{\kappa}<\prod_{s}\left(\beta_{i s} \frac{\sum_{g} y_{i g} x_{i g}}{\sum_{g} x_{i g}^{1-\kappa} \pi_{i g s} y_{i g}}\right)^{\beta_{i s}} .
$$

This can be rewritten as

$$
\prod_{s}\left(\sum_{g}\left(\frac{x_{i g}}{\sum_{m} y_{i m} x_{i m}}\right)^{1-\kappa} \pi_{i g s} y_{i g}\right)^{\beta_{i s}}<\prod_{s} \beta_{i s}^{\beta_{i s}},
$$

where $y_{i g}, \beta_{i s}, \pi_{i g s}$ are all between zero and one, and

$$
\sum_{s} \beta_{i s}=\sum_{s} \pi_{i g s}=\sum_{g} y_{i g}=1
$$


To proceed, let $z_{i s} \equiv \sum_{g}\left(\frac{x_{i g}}{\sum_{m} y_{i m} x_{i m}}\right)^{1-\kappa} \pi_{i g s} y_{i g}$ and note that

$$
\sum_{s} z_{i s}=\sum_{g}\left(\frac{x_{i g}}{\sum_{m} y_{i m} x_{i m}}\right)^{1-\kappa} y_{i g} \leq 1
$$

where the inequality comes from the fact that $\kappa$ is positive combined with the power mean inequality, which implies that

$$
\left(\sum_{g} y_{i g} x_{i g}^{1-\kappa}\right)^{1 /(1-\kappa)} \leq \sum_{g} y_{i g} x_{i g}
$$

To finish the proof, note that if $\sum_{s} z_{i s} \leq 1$ and $z_{i s}>0$ for all $s$ then we must have

$$
\prod_{s} z_{i s}^{\beta_{i s}} \leq \prod_{s} \beta_{i s}^{\beta_{i s}}
$$

with equality only if $z_{i s}=\beta_{\text {is }}$ for all $s$. We now show that if $r_{i s} \neq \beta_{i s}$ for some $s$ then we must have $z_{i s} \neq \beta_{i s}$ for some $s$. We do so by contradiction: imagine that $r_{i s} \equiv$ $\sum_{g} \pi_{i g s} y_{i g} \neq \beta_{i s}$ for some $s$ and that $z_{i s}=\beta_{i s}$ for all $s$. Plugging from the definition of $x_{i g}$ into Equation 26 and rearranging we see that $\hat{w}_{i s}$ for $s=1, \ldots, S$ is determined from the system of equations given by

$$
\beta_{i s} \sum_{g}\left(\sum_{k} \pi_{i g k} \hat{w}_{i k}^{\kappa}\right)^{1 / \kappa} y_{i g}=\sum_{g} \frac{\hat{w}_{i s}^{\kappa}}{\sum_{k} \pi_{i g k} \hat{w}_{i k}^{\kappa}}\left(\sum_{k} \pi_{i g k} \hat{w}_{i k}^{\kappa}\right)^{1 / \kappa} \pi_{i g s} y_{i g}
$$

for $s=1, \ldots, S$. For future purposes, note that $\hat{w}_{i s}=1$ for all $s$ is not a solution given that, by assumption, $\sum_{g} \pi_{i g s} y_{i g} \neq \beta_{i s}$ for some $s$. Solving for $\beta_{s}$ from this equation, we see that $z_{s}=\beta_{s}$ is equivalent to

$$
\sum_{g}\left(\frac{\left(\sum_{k} \pi_{i g k} \hat{w}_{i k}^{\kappa}\right)^{1 / \kappa}}{\sum_{h}\left(\sum_{k} \pi_{i h k} \hat{w}_{i k}^{\kappa}\right)^{1 / \kappa} y_{i h}}\right)^{1-\kappa} \pi_{i g s} y_{i g}=\sum_{g} \frac{\hat{w}_{i s}^{\kappa}}{\sum_{k} \pi_{i g k} \hat{w}_{k}^{\kappa}} \frac{\left(\sum_{k} \pi_{i g k} \hat{w}_{i k}^{\kappa}\right)^{1 / \kappa}}{\sum_{h}\left(\sum_{k} \pi_{i h k} \hat{w}_{i k}^{\kappa}\right)^{1 / \kappa} y_{i h}} \pi_{i g s} y_{i g} .
$$

Simplifying, this is equivalent to

$$
\sum_{g}\left(\sum_{k} \pi_{i g k} \hat{w}_{i k}^{\kappa}\right)^{1 / \kappa} y_{i g}=\hat{w}_{i s}
$$


The only solution to this system is $\hat{w}_{i s}=1$ for all $s$, but we know that this is not possible. This establishes a contradiction and shows that if $\sum_{g} \pi_{i g s} y_{i g} \neq \beta_{i s}$ for some $s$ then $z_{i s} \neq$ $\beta_{i s}$ for some $s$. This finishes the proof.

\section{Appendix D Intermediate Goods}

Here we provide the background for the extended model in Section 7.1, and prove Proposition 3.

Combining equations (22) and (23) yields

$$
P_{j s}=\gamma_{s}^{-1}\left(\sum_{i} T_{i s}\left(\tau_{i j s} w_{i s}^{\left(1-\alpha_{i s}\right)} \prod_{k} P_{i k}^{\alpha_{i k s}}\right)^{-\theta_{s}}\right)^{-1 / \theta_{s}}
$$

Given wages, this equation represents a system of $N \times S$ equations in $P_{j s}$ for all $j$ and $s$, which can be used to solve for $P_{j s}$ and hence $c_{i s}$ and $\lambda_{i j s}$ given wages. This implies that trade shares are an implicit function of wages. Letting $X_{j s}$ and $R_{j s}$ be total expenditure and total revenues for country $j$ on sector $s$, then $R_{i s}=\sum_{j=1}^{n} \lambda_{i j s} X_{j s}$, while CobbDouglas preferences and technologies imply that $X_{j s}=\beta_{j s}\left(Y_{j}+D_{j}\right)+\sum_{k=1}^{S} \alpha_{j s k} R_{j k}$, where $D_{j}$ are trade imbalances satisfying $\sum_{j} D_{j}=0$. These equations constitute a system of linear equations that we can use to solve for revenues given income levels and trade shares,

$$
R_{i s}=\sum_{j} \lambda_{i j s}\left(\beta_{j s} Y_{j}\left(1+d_{j}\right)+\sum_{k=1}^{S} \alpha_{j s k} R_{j k}\right)
$$

where $d_{j} \equiv D_{j} / Y_{j}$. Since trade shares and income levels themselves are a function of wages, this implies that revenues are a function of wages. The excess demand for efficiency units in sector $s$ of country $i$ is now

$$
E L D_{i s} \equiv \frac{\left(1-\alpha_{i s}\right)}{w_{i s}} R_{i s}-\sum_{g \in G_{i}} E_{i g s} .
$$

As in the baseline model, the system $E L D_{i s}=0$ for all $i$ and $s$ is a system of equations that we can use to solve for wages. In turn, given wages we can solve for all the other variables of the model. 
The next step is to write the hat algebra system. From $E L D_{i s}^{\prime}=0$ we get

$\sum_{g \in G_{i}} \hat{\pi}_{i g s} \hat{\Phi}_{i g} \pi_{i g s} Y_{i g}=\left(1-\alpha_{i s}\right) \sum_{j=1}^{n} \lambda_{i j s} \hat{\lambda}_{i j s}\left(\beta_{j s}\left(\sum_{g \in G_{j}} \hat{\Phi}_{j g} Y_{j g}\left(1+\hat{d}_{j} d_{j}\right)\right)+\sum_{k=1}^{S} \alpha_{j s k} \hat{R}_{j k} R_{j k}\right)$

where $\hat{\Phi}_{i g}$ is as in (8) and

$$
\begin{gathered}
\hat{\lambda}_{i j s}=\frac{\hat{T}_{i s}\left(\hat{\tau}_{i j s} \hat{w}_{i s}^{1-\alpha_{i s}} \prod_{k} \hat{P}_{i k}^{\alpha_{i k s}}\right)^{-\theta_{s}}}{\sum_{l} \lambda_{l j s} \hat{T}_{l s}\left(\hat{\tau}_{l j s} \hat{w}_{l s}^{1-\alpha_{l s}} \prod_{k} \hat{P}_{l k}^{\alpha_{l k s}}\right)^{-\theta_{s}}}, \\
\hat{P}_{j s}^{-\theta_{s}}=\sum_{i} \lambda_{i j s} \hat{T}_{i s}\left(\hat{\tau}_{i j s} \hat{w}_{i s}^{\left(1-\alpha_{i s}\right)} \prod_{k} \hat{P}_{i k}^{\alpha_{i k s}}\right)^{-\theta_{s}},
\end{gathered}
$$

and

$$
\hat{R}_{i s} R_{i s}=\sum_{j} \lambda_{i j s} \hat{\lambda}_{i j s}\left(\beta_{j s}\left(\sum_{g \in G_{j}} \hat{\Phi}_{j g} Y_{j g}\left(1+\hat{d}_{j} d_{j}\right)\right)+\sum_{k=1}^{S} \alpha_{j s k} \hat{R}_{j k} R_{j k}\right) .
$$

For welfare analysis, it is useful to fully solve for $\left\{P_{j s}\right\}$ in terms of trade shares. We start with $\lambda_{j j s}=T_{j s} c_{j s}^{-\theta_{s}} /\left(\gamma_{s} P_{j s}\right)^{-\theta_{s}}$, which implies that

$$
\ln P_{i s}=\ln \left(\gamma_{s}^{-1}\left(T_{i s} / \lambda_{i i s}\right)^{-1 / \theta_{s}} w_{i s}^{1-\alpha_{i, s}}\right)+\sum_{k} \alpha_{i k s} \ln P_{i k}
$$

Letting $A_{i} \equiv\left\{\alpha_{i k s}\right\}_{k, s=1, \ldots, S}\left(\operatorname{an} S \times S\right.$ matrix), $B_{i} \equiv\left\{\ln \left(\gamma_{s}^{-1}\left(T_{i s} / \lambda_{i i s}\right)^{-1 / \theta_{s}} w_{i s}^{1-\alpha_{i s}}\right)\right\}_{s=1, \ldots, S}$ (an $S \times 1$ matrix) and $X_{i} \equiv\left\{\ln P_{i s}\right\}_{s=1, \ldots, S}($ an $S \times 1$ matrix), then we have

$$
X_{i}=\left(I-A_{i}^{T}\right)^{-1} B_{i}
$$

where $I$ is the $S \times S$ identity matrix. Letting $\widetilde{a}_{i s k}$ be the typical element of $\left(I-A_{i}^{T}\right)^{-1}$, then we see that

$$
P_{i s}=\prod_{k}\left(\gamma_{s}^{-1}\left(T_{i k} / \lambda_{i i k}\right)^{-1 / \theta_{s}} w_{i k}^{1-\alpha_{i k}}\right)^{\tilde{a}_{i s k}}
$$


This implies that welfare changes for group $i g$ are given by

$$
\frac{\hat{Y}_{i g}}{\hat{P}_{i}}=\frac{\hat{\Phi}_{i g}^{1 / \kappa_{i g}}}{\prod_{s, k}\left(\hat{\lambda}_{i i k}^{1 / \theta_{s}} \hat{w}_{i k}^{1-\alpha_{i k}}\right)^{\beta_{i s} \widetilde{a}_{i s k}}} .
$$

In general, we can check that $\sum_{k}\left(1-\alpha_{i, k}\right) \widetilde{a}_{i, s k}=1$, and hence $\sum_{s, k}\left(1-\alpha_{i, k}\right) \beta_{i s} \widetilde{a}_{i, s k}=$ 1 , so we can rewrite the above result as

$$
\frac{\hat{Y}_{i g}}{\hat{P}_{i}}=\frac{1}{\prod_{s, k}\left(\hat{\lambda}_{i i k}^{1 / \theta_{s}} \hat{\Phi}_{i g}^{-\left(1-\alpha_{i k}\right) / \kappa_{i g}} \hat{w}_{i k}^{1-\alpha_{i k}}\right)^{\beta_{i s} \widetilde{a}_{i s k}}}
$$

But then, using $\hat{w}_{i s} \hat{\Phi}_{i g}^{-1 / \kappa_{i g}}=\hat{\pi}_{i g s}^{1 / \kappa_{i g}}$, we get

$$
\frac{\hat{Y}_{i g}}{\hat{P}_{i}}=\frac{1}{\prod_{s, k}\left(\hat{\lambda}_{i i k}^{1 / \theta_{s}} \hat{\pi}_{i g k}^{\left(1-\alpha_{i k}\right) / \kappa_{i g}}\right)^{\beta_{i s} \widetilde{a}_{i s k}}} .
$$

This establishes the result in Proposition 3. 